\title{
Analysis of Tensile-Shear Strength of Single and Multi- FSSW Joints under fixed welding process conditions
}

\author{
Morteza Asadollahi ${ }^{1}$, Neda Jabbari ${ }^{1}$, Soheil Nakhodchi ${ }^{1 *}$, Hossein Salimi ${ }^{1}$, Hamed Haddad \\ Khodaparast $^{2}$ \\ ${ }^{\mathbf{1}}$ Faculty of Mechanical Engineering, K. N. Toosi University of Technology, Tehran, Iran \\ ${ }^{2}$ College of Engineering, Swansea University, Swansea, UK \\ *Corresponding author: Dr. Soheil Nakhodchi, Assistant Professor at the Faculty of \\ Mechanical Engineering, K. N. Toosi University of Technology, Tehran, Iran , P.O.B. 19919- \\ 43344, e-mail: snakhodchi@kntu.ac.ir, Tel: +982188674747, Fax: +982188674748
}

\begin{abstract}
The tensile-shear strength of AA 5052 single and multi-FSSW joints were analyzed using experimental, numerical, and analytical approaches. Benchmark specimens were designed and manufactured in a similar manner with respect to industrial practice. Under the fixed welding process condition, the failure mechanism of FSSW-ed specimens under tensile-shear loading was first determined by using macro- and micro-structural analysis. It is shown that increasing the shoulder diameter and number of FSSWs may non-proportionally increase the strength of the joints. In the linearly arranged multi-FSSW joints, the strength of these joints was discussed using analytical approach. It is demonstrated that in certain cases, increasing the nugget diameter is preferred than increasing the number of nuggets. This is only applicable to a certain FSSW failure mechanism. A FE model prediction tool was developed to predict the tensile-shear strength of FSSW-ed joints using the material properties obtained from the measurement of experimental hardness.
\end{abstract}

Keywords: Friction stir spot weld, tensile-shear strength, Multi-spot welding

\begin{tabular}{|l|l|}
\hline Symbol & Description \\
\hline$r_{n}$ & Radial distance from the centroid to the center of $n$th weld nugget \\
\hline$F_{0}$ & Reaction of each nugget toward in-plane shear force \\
\hline$F^{\prime \prime}{ }_{n}$ & Substitution force of $n$th nugget \\
\hline $\mathrm{V}_{1}$ & In-plane shear force \\
\hline $\mathrm{M}_{1}$ & Out-of -plane moment \\
\hline $\mathrm{G}$ & Centroid point \\
\hline $\mathrm{D}$ & Diameter of tool shoulder \\
\hline UTSF & Ultimate tensile shear force \\
\hline
\end{tabular}

\section{Introduction}


One of the new solid state welding procedures is friction stir welding (FSW), which has been widely used to weld aluminum alloys. This technique could be used for joining parts without melting the base materials. Friction stir spot welding (FSSW) was then derived from FSW to overcome the disadvantages of resistant spot welding (RSW), such as contamination, blowholes, porosity, and cracks in the weld region. This procedure was first introduced by The Welding Institute (TWI) and it was later commercialized by the Mazda Corporation of Japan (Hancock 2004). Feng (Feng et al. 2005) suggested to divide the FSSW procedure into three steps of plunging, stirring, and retracting. A rotating tool is plunged into two overlapping sheets in a single location. Then, the tool dwells for a specific time (about 2-5 seconds) allowing the materials mix together. Finally, the tool is drawn out and the bond is generated. FSSW can be used for joining dissimilar sheets while the weld nugget experiences low distortion during and after the welding procedure. Its benefits include possessing a small amount of waste material and energy savings of about 90 percent in comparison to RSW. Furthermore, in controlling the process parameters, different authors such as Hancock (Su et al. 2007), Su (Su et al. 2007) and Lin (Lin et al. 2012) have been reported that FSSW can generate joints with higher mechanical properties in comparison to RSW. As a result of these advantages, FSSW is used to weld lightweight materials, especially aluminum alloys. Two review studies published by pan (Pan 2007) and Yang (Yang et al. 2014) provided comprehensive data on microstructures, mechanical properties, and the fatigue behavior of FSSW in different materials.

Bilici (Bilici and Yükler 2012) demonstrated that the load-bearing capacity of the FSSW joints is one of the most important mechanical properties that is mainly affected by the sizes of the weld zones. Addison (Addison and Robelou 2004) showed the size and shape of the weld zone also depends on the conditions and parameters of the welding process. These factors can be divided into two major categories of welding parameters, such as tool rotational speed, dwell time, delay time, plunge depth, and plunge rate as well as tool geometrical factors, such as pin diameter, pin length, pin angle, pin profile, shoulder diameter, and the shoulder concavity angle. The research presented by Mishra (Mishra and Ma 2005) and Khosa (Khosa et al. 2010) showed that in a fixed welding process parameter, the heat generation and plastic flow of the material are only affected by tool geometrical factors. The previous studies were mainly focused on obtaining optimum FSSW joints by changing the various affecting parameters. Tozaki (Tozaki et al. 2006) showed that the bond strength of aluminum alloys is proportional to the pin length. Lin (Lin et al. 2013) used threaded cylindrical pins and demonstrated further increase of the FSSW joint strength by varying the material flow; there is, however, no exact quantification at this point. Yuan's work was focused on the pin's rotational direction and they change the lap-shear strength by modifying the rotational direction (clockwise and counter-clockwise) of a threaded pin.

Although multi-FSSWs are mostly used in industries rather than single FSSW, among the few studies performed on multi-FSSW joints, only Adib (Adib et al. 2004) and Hassanifard (Hassanifard et al. 2013) reported fatigue life of multi-FSSW joints and no study was found that examined the ultimate strength and mechanical behavior of these types of joints. FE simulations were mainly focused on the distribution of heat and material flows under 
different conditions. Several methods and software tools were used in the FSSW analysis. Langerman (Langerman and Edvin 2003) used FLUENT software for computational fluid dynamic (CFD) analysis. These methods used non-Newtonian fluid assumption and temperature distribution, and the flow of metals was predicted. Dorfeler (Dörfler 2008) used the written CFD code in COMSOL for simulating dissimilar joints. FE codes, such as the ABAQUS software that were used by Gerlich (Gerlich et al. 2005) and Awang (Awang and Mucino 2010) were also employed for temperature and deformation predictions.

The main objective of the current research was to simulate an industrial case in which the designer should increase the overall strength of the joints by increasing the weld nugget diameter or increasing the number of the spot welds. In the presented approach, the failure mechanism of the predefined FSSW joints, which were made of 5052 aluminum, was first determined. Then, by increasing the number of nuggets and tool shoulders, the tensile-shear strength was measured. It was shown that the presented analytical approach can be used for predicting the effect of the number nuggets in linearly arranged multi-FSSW joints. A simple FE modeling prediction tool was developed based on experimental measurement of material hardness.

\section{Experiments}

\subsection{Materials, Tools, and Welding Experiments}

Single and multiple FSSW experiments were conducted on rectangular specimens with a length of $200 \mathrm{~mm}$ and a width of $30 \mathrm{~mm}$, which were cut from a 2-mm thick aluminum alloy 5052-H36 sheet. Owing to the presence of magnesium, AA 5052 has good corrosion resistance and it is widely used in the aerospace, automotive, and marine industries. The chemical composition of the material was measured and it is listed in Table 1. The mechanical properties are listed in Table 2.

Table 1 Chemical composition of 5052 Al alloy

\begin{tabular}{|c|c|c|c|c|c|c|}
\hline Element & $\mathrm{Al}$ & $\mathrm{Mg}$ & $\mathrm{Fe}$ & $\mathrm{Cr}$ & Sc & Others \\
\hline $\begin{array}{c}\text { Weight } \\
\text { percentage }\end{array}$ & Rest & 2.5 & 0.4 & 0.25 & 0.25 & 0.45 \\
\hline
\end{tabular}

Table 2 Mechanical properties of 5052 Al alloy

\begin{tabular}{|c|c|}
\hline Mechanical property & Unit \\
\hline Yield stress & $241 \mathrm{MPa}$ \\
\hline Ultimate stress & $276 \mathrm{MPa}$ \\
\hline Elongation & $8 \%$ \\
\hline
\end{tabular}

In order to investigate the effect of tool diameter, four tools were made of a round bar of AISI H13 chromium hot-work tool steel. The shoulder diameters were machined to $6.5 \mathrm{~mm}, 10$ $\mathrm{mm}, 13 \mathrm{~mm}$, and $16 \mathrm{~mm}$, with concave profiles. All the pins were conical unthreaded pins, with a length of $2.75 \mathrm{~mm}$ and an apex angle of 15 degrees. The angle of the chamfer within 
the shoulder end surface was 5 degrees. All the tools were quench and temper heat-treated to 50 HRC. Figure 1a) shows the schematic view of tool geometry.

The joints were spot welded by using a FP4ME CNC milling machine, with a vertical speed of $12 \mathrm{~mm} /$ minute, a plunge depth of $3.1 \mathrm{~mm}$, and dwell time of 5 seconds. The tool rotation speed was fixed at 2500 RPM. The weld specimens were manufactured by overlapping two sheets over a length of $40 \mathrm{~mm}$ for single FSSW, where the FSSW process was then performed at the center of the overlap. For multiple FSSW specimens, the typical overlap length and the location of the spot welds in the specimens with two and three spot welds are also shown in Figures 1b) and 1c) respectively. To prevent the stress concentration effect, the distance between the center of the nugget and the edge of the sheet was maintained at $15 \mathrm{~mm}$. A gap of $30 \mathrm{~mm}$ was also considered between the two weld centers. A typical view of the welded joints using tools with different shoulder diameter is shown in Figure 2.

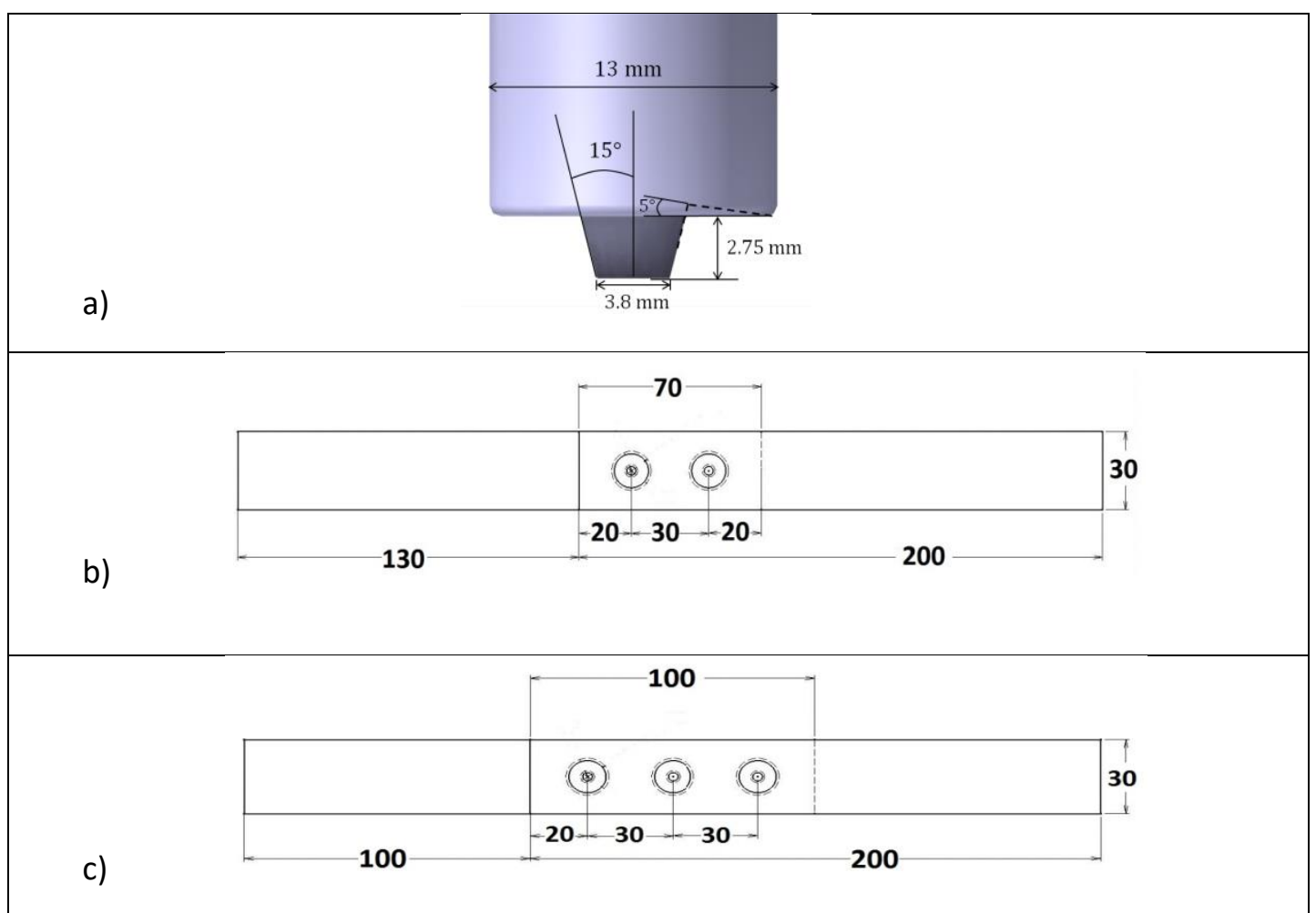

Figure 1a) Schematic geometry of FSSW tool and typical dimension of multiple FSSW specimens 1b) two-spot welds and 1c) three spot-welds (Dimensions are in $\mathrm{mm}$.) 


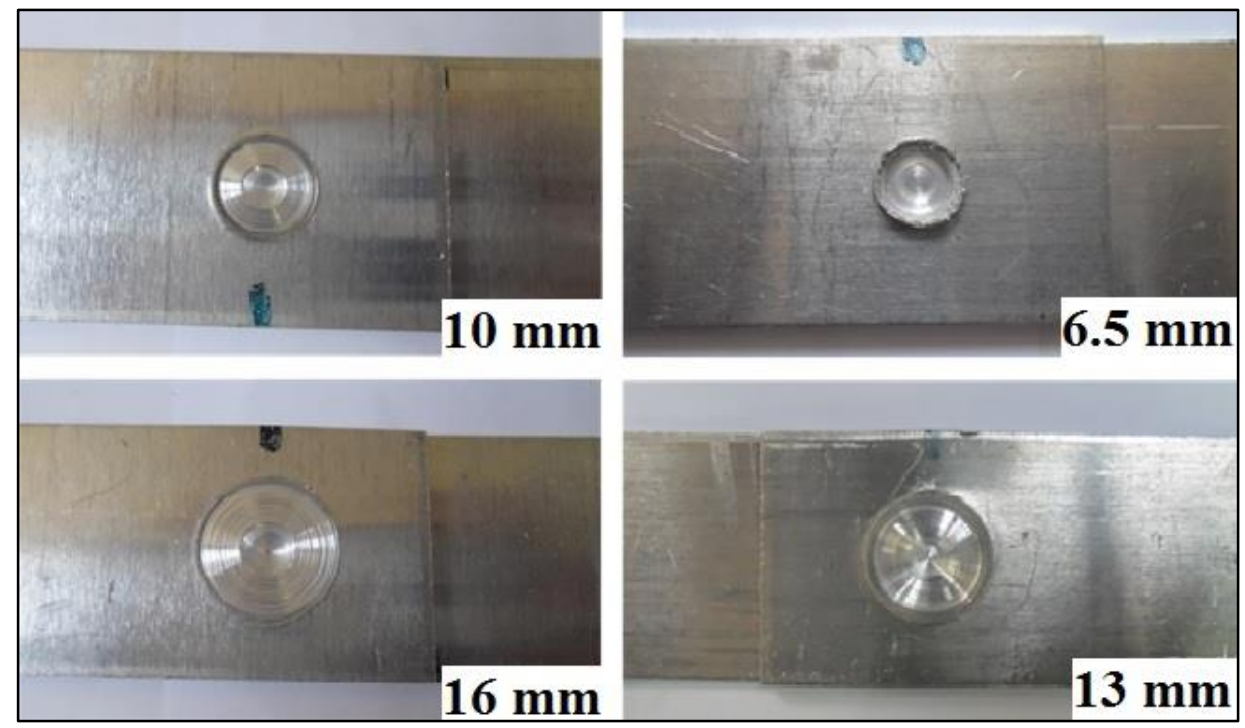

Figure 2 Welded specimens with single spot weld and different tools shoulder diameter

\subsection{Tensile-shear Test}

The tensile-shear tests were performed at room temperature under displacement control at a rate of $1 \mathrm{~mm} /$ minute by using a 'Shijin-Class A' uniaxial testing machine. In order to align the applied loads under the lap-shear loading conditions, two doublers, made of the same material with a dimension of $30 \mathrm{~mm} \times 30 \mathrm{~mm}$, were bonded to the ends of the specimens by using metal adhesives. Several tensile-shear experiments were performed and each test was repeated at least three times, full load-displacement curves of each geometry configuration were then obtained. The tool shoulder diameter and the number of FSSWs were changed to simulate industrial practice.

\subsection{Macrostructure and Microstructure Observations}

In order to characterize the deformation mechanism in each of the sections shown in Figure 3, further tests were conducted and in each test, the specimen was loaded only till the maximum force was associated in each section. The specimen was then cross-sectioned by using an electrical-discharge cutting machine (EDM). The cross-sectioned samples were mounted in Bakelite and they were grounded with emery papers up to 1,200 grit. A chemical etchant, a diluted solution of $5 \mathrm{~mL}$ of $\mathrm{HF}+10 \mathrm{~mL}$ of $\mathrm{H}_{2} \mathrm{SO}_{4}$ in $85 \mathrm{~mL}$ of water treated for about 60 to 90 secondswas then used to observe the microstructure of the weld region. Finally, the images were captured in different magnifications by using a Nikon optical microscope (Jenaval, Carl Zeiss/Jena).

\subsection{Micro-hardness Measurement}

Vickers micro-hardness tests were carried out at the cross-section of the weld region on both sheets. A cross-section plane was chosen perpendicular to the loading direction. The hardness 
of the weld region was measured by using a diamond pyramid indenter with $100 \mathrm{~g}$ load and 10 seconds of dwell time.

\section{Experimental Results}

A typical force-displacement diagram for the 13-mm shoulder diameter of the single FSSW is shown in Figure 3, where it is also divided into five sections; these five sections illustrate the different mechanical behaviors of the sample during loading. Further tensile-shear tests were performed on loads associated with each section. This is explained further in the section below.

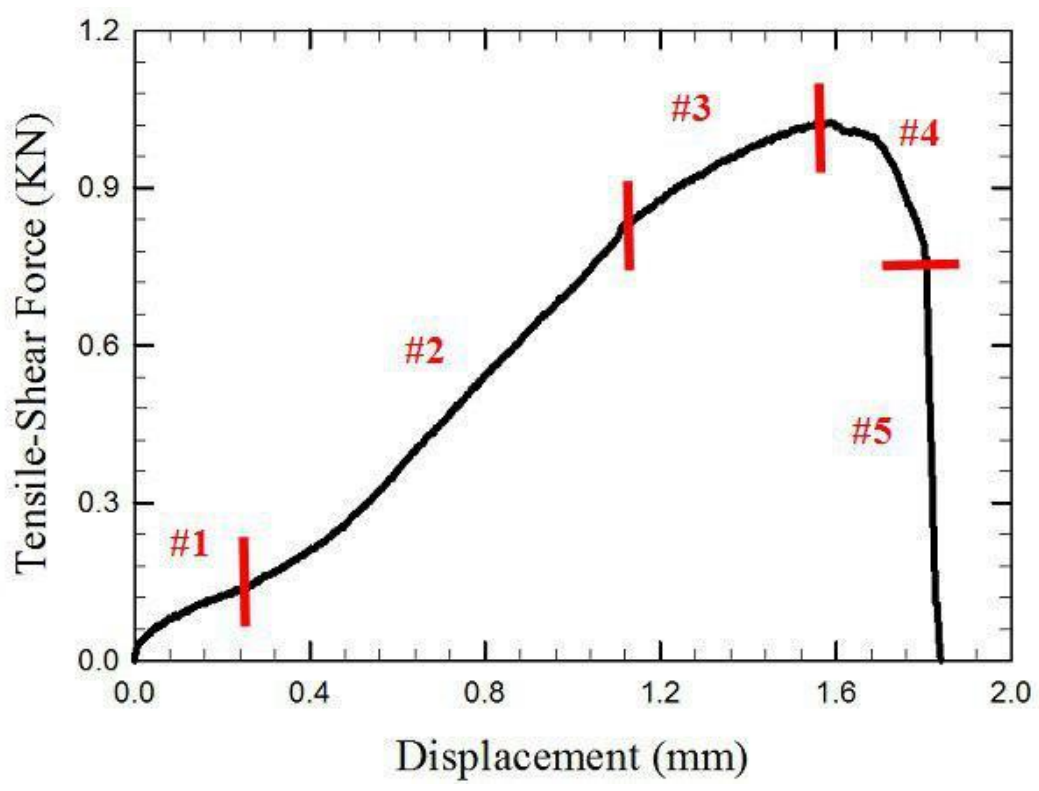

Figure 3 Force-displacement curve for one spot welded specimen. \#1: gripping and balancing the specimen; \#2: elastic deformation; \#3: weld nugget rotation and reaching to UTTS; \#4: shear fracture; \#5: joint separation

The variation of tensile-shear force with the displacement of tools having different shoulder diameters is shown in Figure 4. Similar results of multiple spot weld specimens are compared in Figure 5. A side view of the deformation experienced by FSSW joints associated with two spot welds is shown in Figure 6.

The overall appearance of the failed nuggets is shown in Figure 7. Figure 8 illustrates the cross-section of the weld that corresponds to the different sections shown in Figure 3. For example, Figure 8a) shows the cross-section of the weld zone corresponding to the single spot weld specimen that is only loaded up to about $150 \mathrm{~N}$ (Figure 3, Section 1). Figure 9 shows the micro-hardness of the upper and the lower sheets relative to their distances from the HAZ center. The error band for each hardness measurement point was also calculated and plotted in Figure 9. 


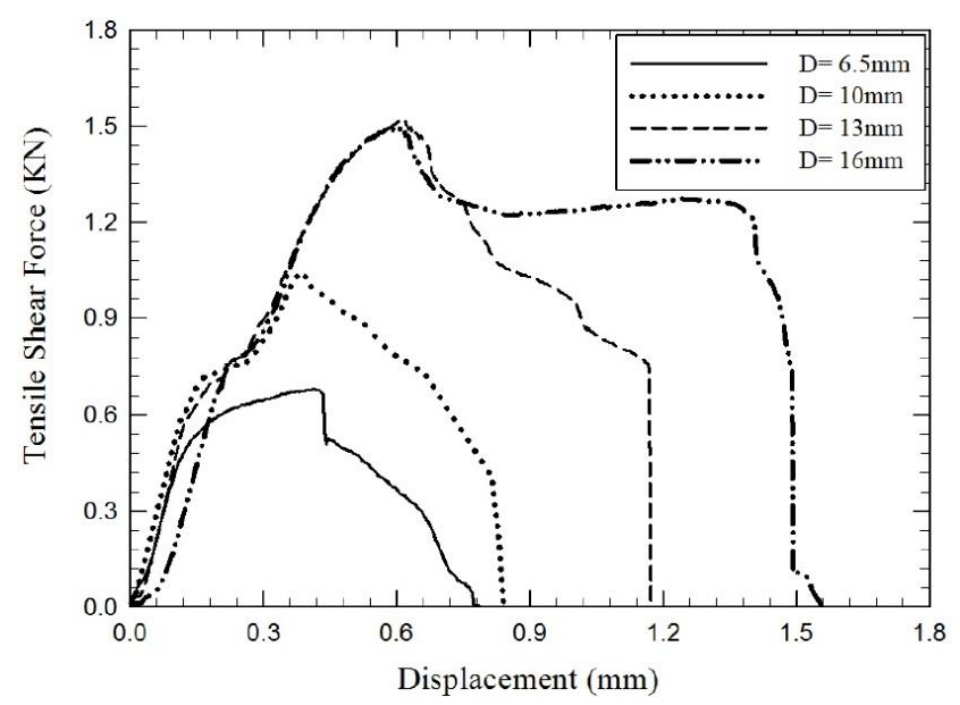

Figure 4 Force-displacement curves for spot welds produced by tools having various shoulder diameters

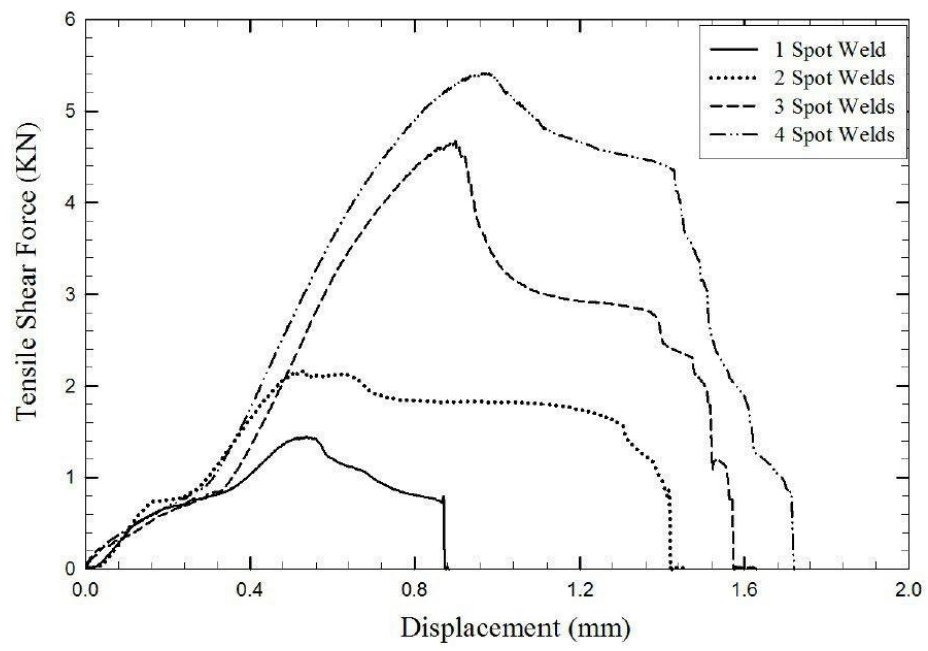

Figure 5 Force-displacement curves for multiple Spot welds

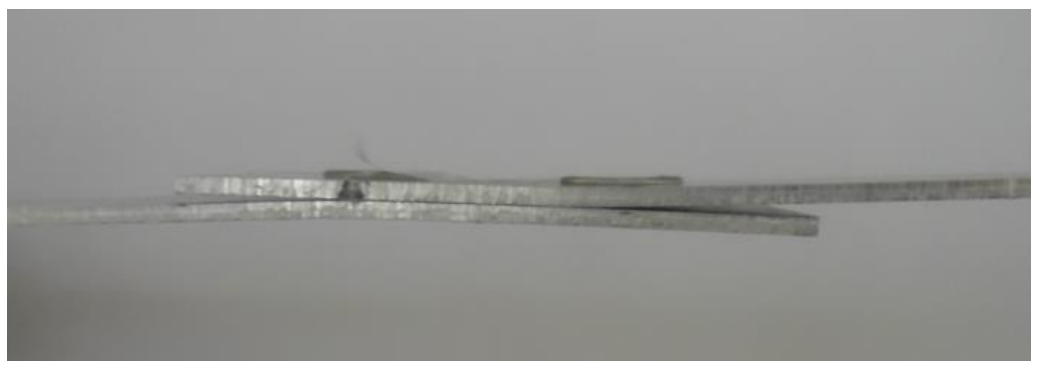

Figure 6 Side view of deformation in the FSSW specimen with two spot weld 


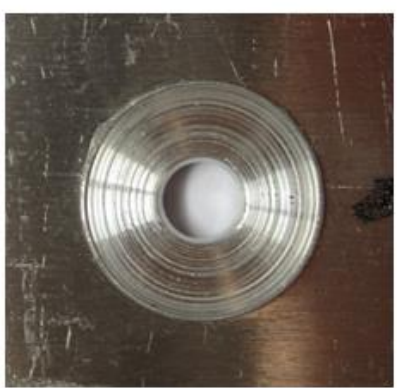

(a)

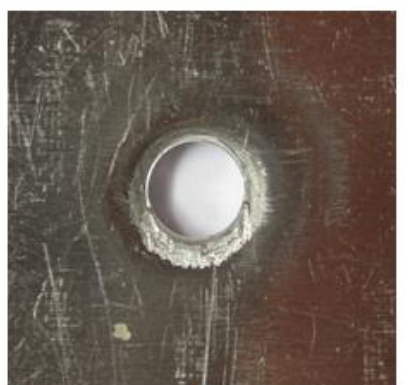

(b)

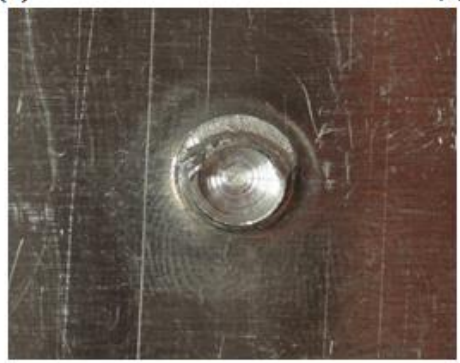

(c)

Figure 7 Surfaces of the failed specimen under tensile shear load, (a) the upside of upper surface, (b) the downside of upper surface, (c) the upside of upper surface

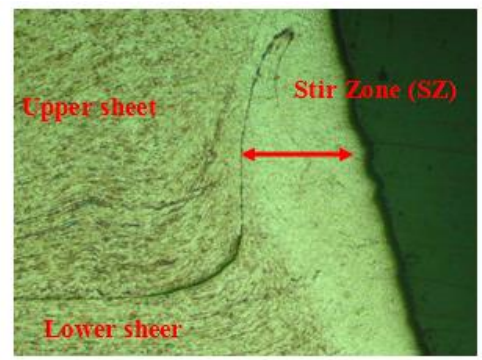

(a)

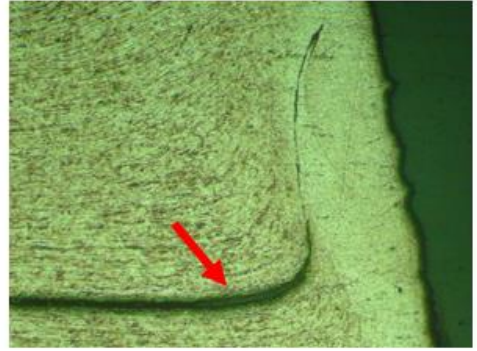

(c)

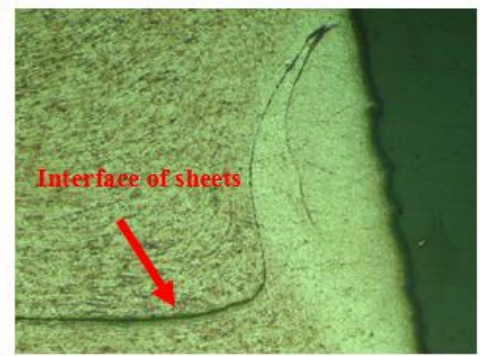

(b)

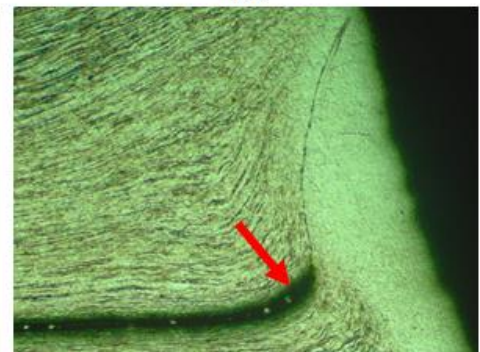

(d)

Figure 8 Macrostructure views of side of the nugget reperesented to (a) section \#1, (b) section \#2, (c) section \#3, (d) section \#4 


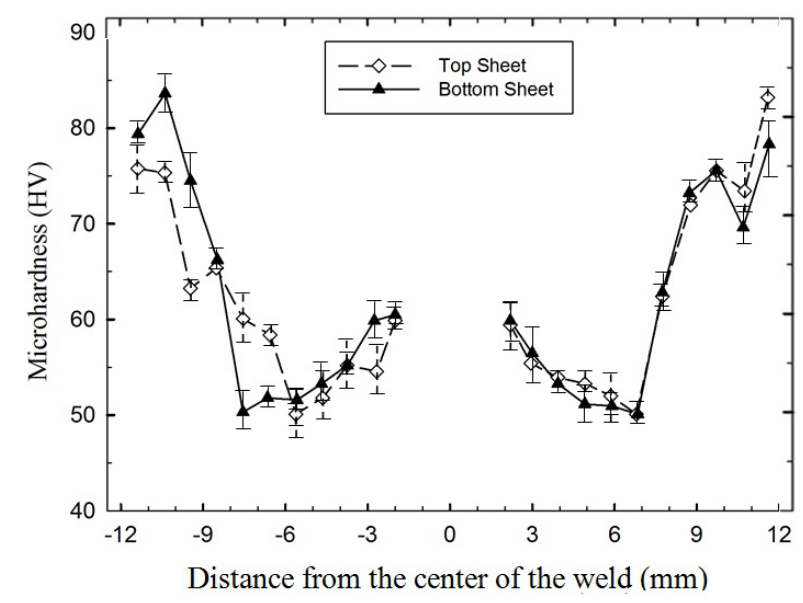

Figure 9 Micro-hardness variations across welding spot for specimen No.3

\section{Finite Element Analysis}

A Finite Element (FE) model of the tensile-shear experiment was developed to simulate the mechanical behavior of the weld under tensile-shear loads. The domain adopted for FE simulation was the 3D model of the entire geometry of FSSW joints with an elastic-plastic constitutive law. A gap of $1 \mu \mathrm{m}$ was considered between the two plates to represent the surface roughness of contact area. During the FSSW process, different weld zones were generated as the results of temperature distribution in the joint area (Fanelli et al. 2012). Hence, the material properties within the weld region varied depending on the distance from the center of the nuggets. There are normally four zones of materials; these are the stir zone (SZ), thermo mechanical affected zone (TMAZ), heat affected zone (HAZ), and base metal (BS). SZ is the innermost zone and is located around the key hole. It is modeled as a hollow sphere in the FE model. In TMAZ, which is farther from the weld center than SZ, the materials are affected both mechanically by the tool and thermally by friction heat. HAZ that is located surrounding TMAZ is considered a hollow cylinder. The BM zone is beyond all zones. While the grains of SZ are recrystallized completely, no changes occur in the properties of the BM zone.

Based on the results presented in the next section, the bonded region extends from center of the weld to the middle of TMAZ. There was no noticeable bonded region beyond this area. Thus, in simulation, SZ and half of TMAZ were considered as an integrated zone. Figure 10 shows the different zones of the material in the FE model. In order to realistically evaluate the welded joint mechanical behavior, detailed geometrical features and accurate material properties were implemented in the FE model. Table 3 presents material properties used in the FE model. As illustrated in Figure 11, fine mesh was adopted for the weld zones, whereas coarser meshes were selected for the other areas. The specimen was fixed from one end and the load was introduced from the other end of the specimen.

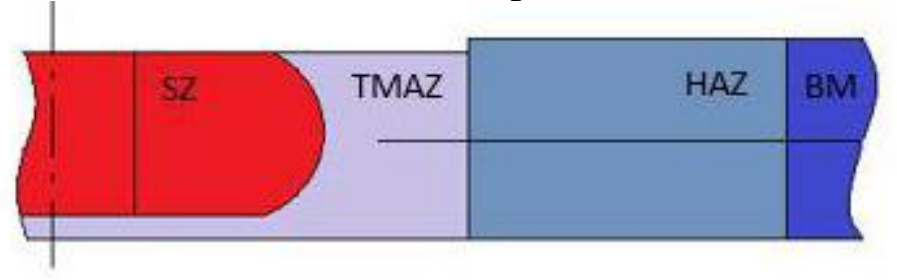

Figure 10 Different zones in FE model 
Table 3 Mechanical properties of different zones in the FE model

\begin{tabular}{|c|c|c|}
\hline Zone in FE model & Mechanical property & Unit \\
\hline \multirow{2}{*}{$\mathrm{BM}$} & Elastic modulus & $210 \mathrm{GPa}$ \\
\cline { 2 - 3 } & Yield Strength & $260 \mathrm{MPa}$ \\
\hline \multirow{2}{*}{$\mathrm{HAZ}$} & Elastic modulus & $125 \mathrm{GPa}$ \\
\cline { 2 - 3 } & Yield Strength & $108 \mathrm{MPa}$ \\
\hline \multirow{2}{*}{ SZ } & Elastic modulus & $125 \mathrm{GPa}$ \\
\cline { 2 - 3 } & Yield Strength & $170 \mathrm{MPa}$ \\
\hline \multirow{2}{*}{ TMAZ } & Elastic modulus & $125 \mathrm{GPa}$ \\
\cline { 2 - 3 } & Yield Strength & $170 \mathrm{MPa}$ \\
\hline
\end{tabular}

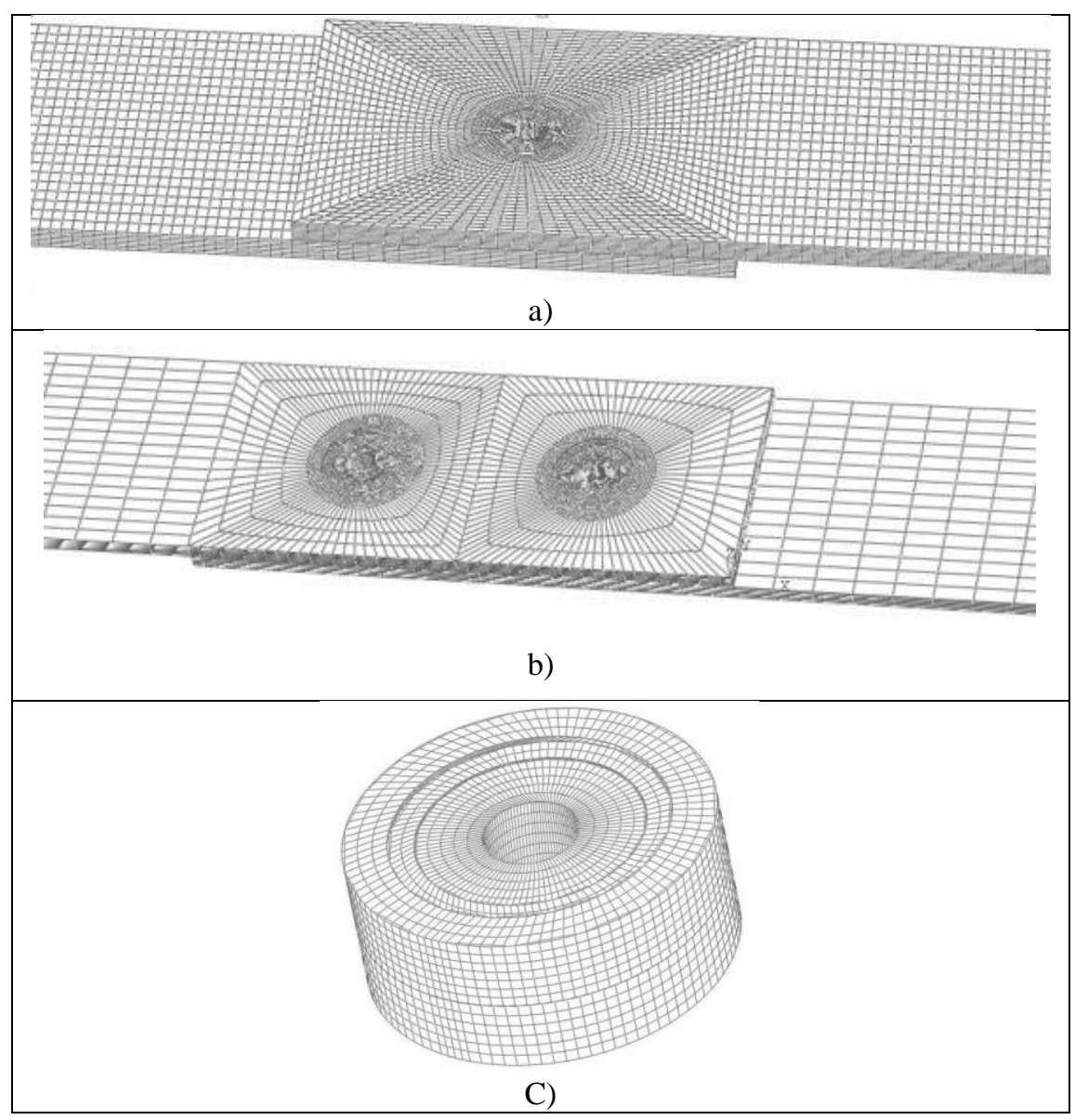

Figure 11 FE Mesh a) single spot b)double spot c) details of FE mesh in the HAZ area

\section{FE Analysis Results}

The main purpose of FE simulation was to develop a FE prediction tool for the determination of the tensile-shear properties of FSSW joint. A better understanding of the mechanical behavior of FSSW joints under tensile-shear loading was also achieved. Figure 12 shows a typical FE results where Figure 12a) illustrates the global deformation of the single FSSW joint. The distribution of the equivalent von Misses stress contour in the tensile-shear specimen is also shown in Figure 12b). 
It could be seen that both shear and tensile loads are applied to the coupon because the coupon rotated. As can be seen in Figure 12, the maximum value of the plastic strain occurred in HAZ region because of a sharp variation of the mechanical properties existed within this zone. The welded joint were failed upon further increasing the load in the FE model prior to interaction forces extended to the other central zones through HAZ region. Furthermore, following the elongation of specimen, the vicinity of the welded area became thinner and the cross sectional area decreased. This results an experience of a higher stress and the joint failure from these regions. This result is coherent with the experimental examinations before-mentioned.

Figure 13 shows the comparison between the force-displacement diagrams obtained from FE simulations and the experiment results for a single FSSW with a different tool diameter. It is obvious that there is a relatively good agreement between these results, and the FE model can predict the mechanical behavior and the yield point of the FSSW joints. The discrepancy can be noted next to the yield point in Figure 13 and the FE simulations underestimates the experimental results due to the fact that the damage properties were not defined for the current FE model. As the tool diameter became smaller, the width of SZ and HAZ decreased. These zones could be neglected in simulation processes of the weld with a $6.5 \mathrm{~mm}$ tool because significant variations in properties did not occur. Thus, the relative errors between simulation and experiment curves increased.

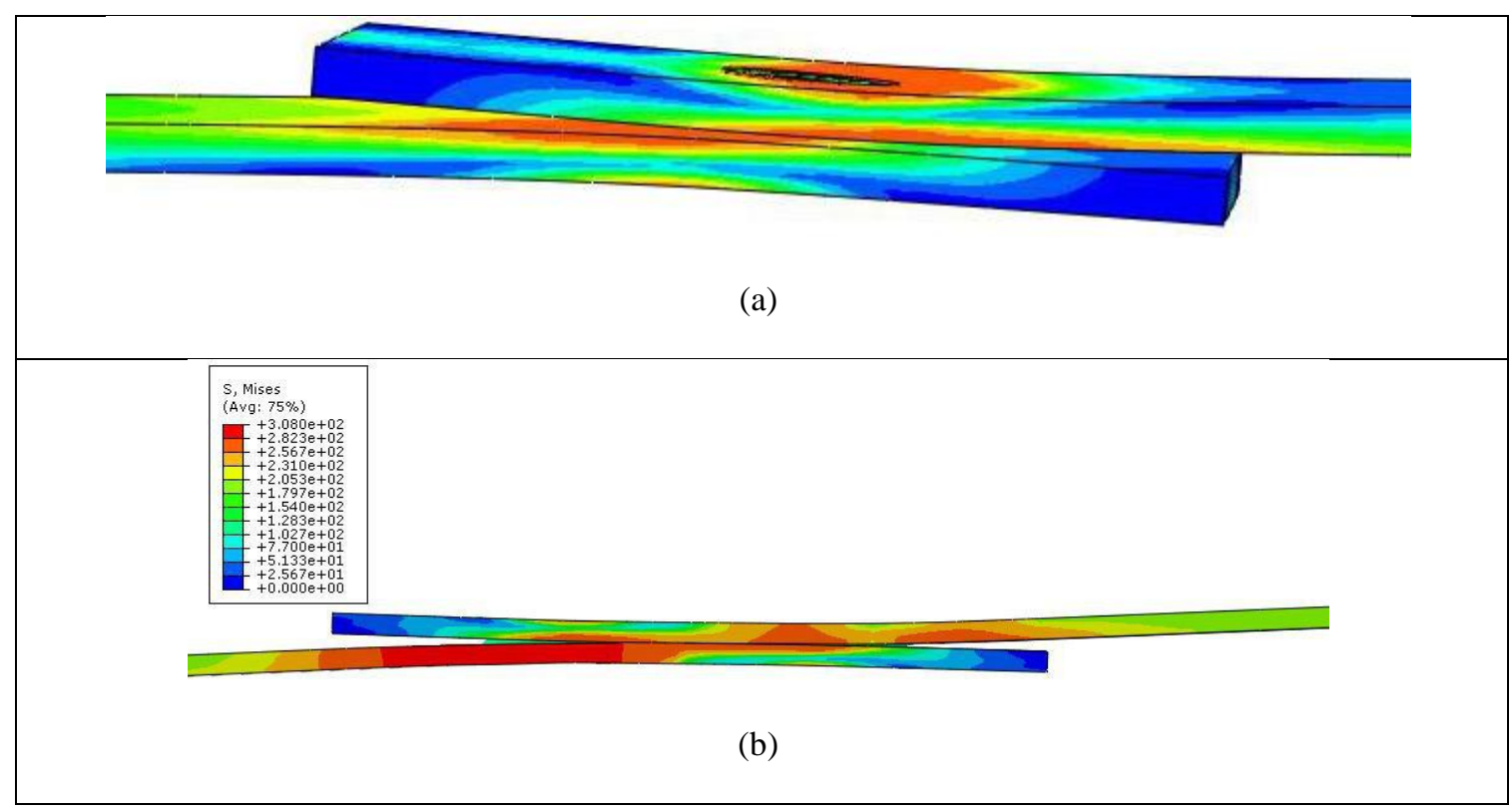

Figure 12 FE deformation and stress distribution in the a) single b) double FSSW 


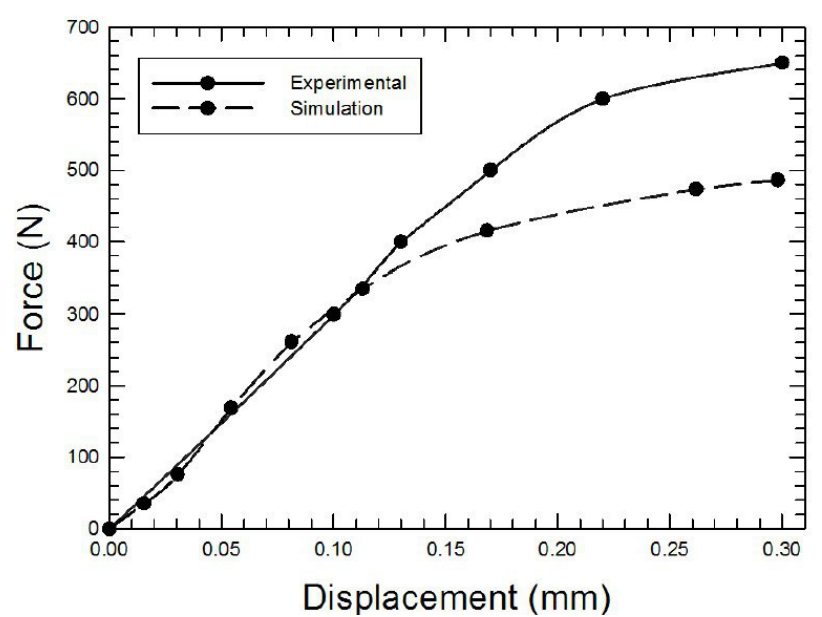

a)

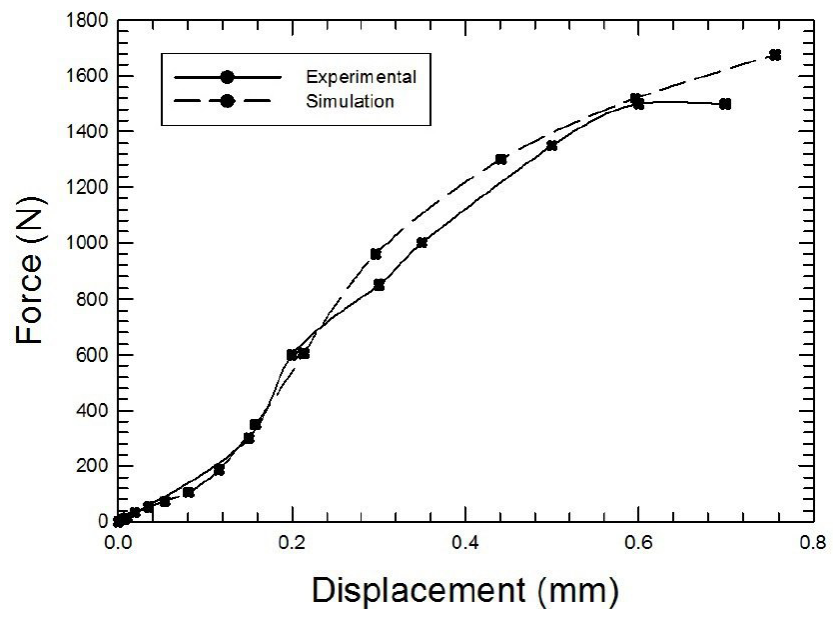

c)

Figure 13 Comparison between experiment and FE simulation a) $6.5 \mathrm{~mm}$

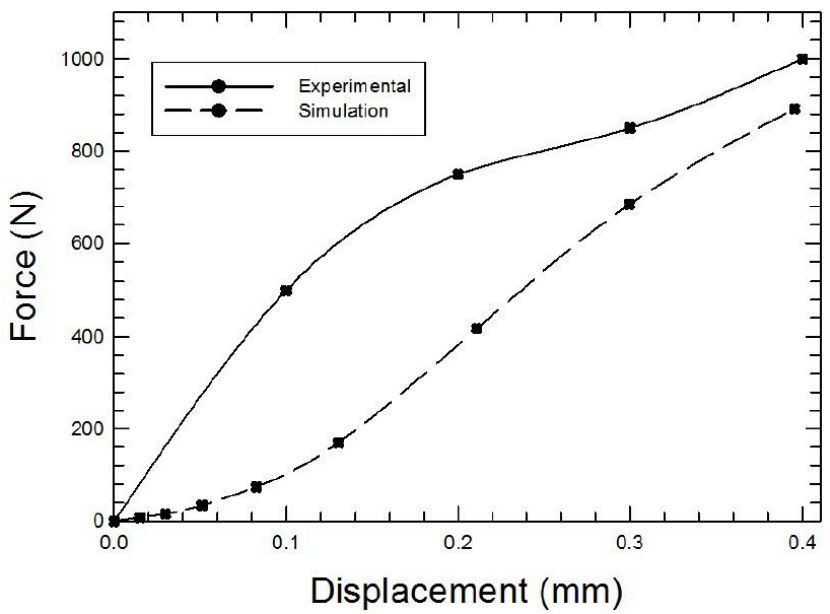

b)

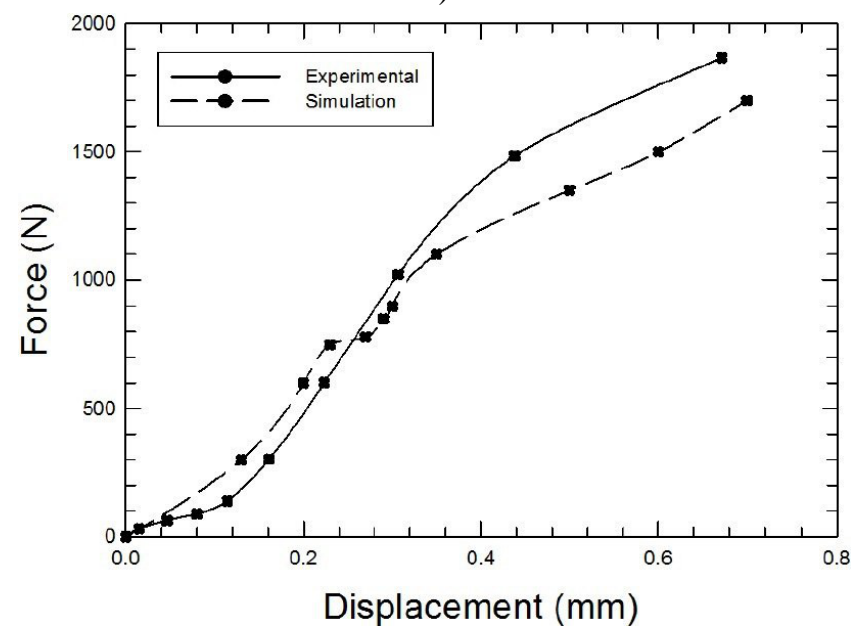

d)

b) $10 \mathrm{~mm} \mathrm{c)} 13 \mathrm{~mm} \mathrm{~d} 16 \mathrm{~mm}$

\section{Discussion}

\subsection{Failure Mechanism, Force-displacement Diagram, Macro and Micro Characterization of a Single FSSW}

Figure 3 represents a typical force-displacement diagram for a single spot weld specimen where the corresponding tensile-shear strength is about $1050 \mathrm{~N}$. This load can also be designated as the "fracture initiation force" as the fracture initiates immediately after this load. It is worth noting that the final fracture of the weld joint normally is attributed to the localization of the deformation within the joint zones. The corresponding total displacement in Figure 3 is about $1.5 \mathrm{~mm}$.

Events observed in Figure 3 were divided into 5 sections. In Section \#1, load was conducted in the testing machine; balancing and tightening the specimen took a few seconds at the beginning of this section. In Section \#2, the curve was raised with a constant slope and the load was increased in proportion with the deformation. By removing the load at the end of Section \#2 and the examination of the specimens, it was observed that the total length of the specimen did not change. Hence, it can be inferred an elastic deformation was experienced by 
the specimens. A similar trend can be seen in Section \#3 with a slightly lower slope, which demonstrates a global elastic deformation with a small amount of plastic deformation across the weld zones. The peak point at the end of this section is the ultimate tensile-shear force (UTSF) limit. The UTSF was slightly over $10 \mathrm{KN}$, corresponding to about $16 \mathrm{~mm}$ of displacement. An out-of-plane rotation can be observed in the test specimen in Section \#3, which can be attributed to a bending moment induced by the weld, which is distributed across all the ungripped length of the specimens. After reaching the peak point, a falling trend starts in Section \#4. It can be seen that the curve drops almost suddenly; thus, the pure shear failure mechanism can be concluded (Paidar et al. 2014). The specimen was separated completely in Section \#5. It is worth noting that the tensile-shear mode failure normally occurs with loaddisplacement that is not dropped suddenly and a residual force remained after the force started to decrease(Marya et al. 2006).

Another way to determine the joint failure mode in FSSW was the observation of the appearance of the surface of the failed nuggets (Zhang et al. 2011). Figure 8 shows the failed nugget surfaces with Figure $8 \mathrm{a}$ ) and $8 \mathrm{~b}$ ) illustrating the upside and the downside of the fractured surfaces of the upper sheet, respectively and Figure 8c) presenting the failed upside surface of the lower sheet. In general, two major fracture mechanisms can occur during the tensile-shear loading of FSSW: the shear fracture mode and the tensile-shear fracture mode (Paidar et al. 2014). The failure surfaces presented in Figure 8 exhibits a typical shear failure mode in which the bonded area around the weld nugget is separated in the faying surfaces near the keyhole. This can be also noted in Figure 8c), which was related to Section \#3, where an increase in the distances between the two interfaces can be seen.

During the FSSW process, the tool shoulder generated a flow of viscous material that pressed materials downward while plunging the pin produced an extra material flow that extruded materials upward and outward. These flows of material together led to the formation of metallurgical bonding. The wider bonded region is, the larger forces the weld can endure (Sarkar et al. 2016). Hook is the location at which the separation line of the sheet interfaces bends and it a critical point in failure (Badarinarayan et al. 2009). Both the width of the bonded region and the hook location are useful for analyzing the macrostructure. 


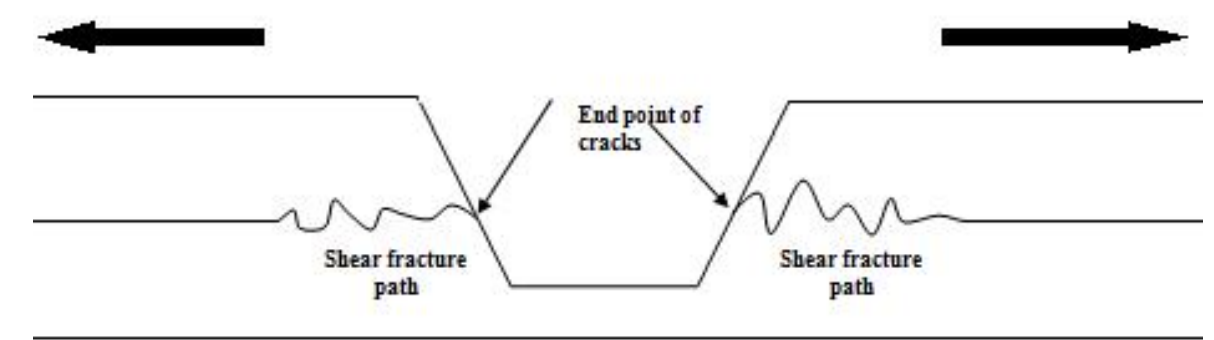

(a)

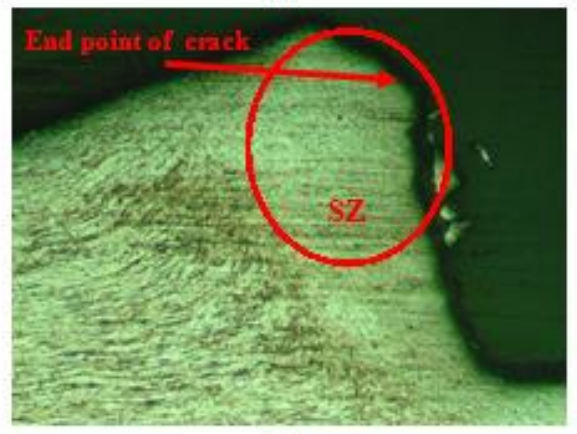

(b)

Figure 14. The crack propagation path under tensile-shear loadings

\section{6-2 Tensile-shear Behavior affected by Tool Shoulder Diameter and Multiple Spot Welding}

Figure 4 illustrates the effect of increasing the tool shoulder diameter on load-displacement behavior. It can be seen that the curves follow the same trend up to the yield point. However, by increasing the shoulder diameter from $6.5 \mathrm{~mm}$ to $13 \mathrm{~mm}$, the average value of UTSF also increased by a factor of 2 from $0.734 \mathrm{KN}$ to $1.507 \mathrm{KN}$. Each test shown in Figure 5 was performed on the three specimens and the UTSF is plotted versus the shoulder diameter in Figure 15. It is can be seen that the UTSF is increased almost linearly up to the specimen, with $13 \mathrm{~mm}$ of shoulder diameter. Then, the UTSF remained almost constant, even with the increasing shoulder diameter of the specimens. This can be attributed to the fact that the volume of the stirred material is a function of pin geometry, which can alter the UTSF (Bozzi et al. 2010). On the other hand, the role of the tool shoulder during FSSW involves forging the softened material. Therefore, in the current experiment, when the pin geometry was kept constant throughout the FSSW experiment, the increase in the shoulder diameter improved the forging force, while the volume of the stirred material was still constant.

Figure 6 shows the variation of tensile-shear force with a displacement in the multi-spot friction stir-welded specimens. As the number of nuggets increase, it can be seen that the general shape of the tensile-shear curves, which also represent the failure mechanism, does not change. Similarly, the UTSF of each test was extracted and plotted versus the number of the spot welds in Figure 16. As mentioned, each test was replicated three times and the line was also plotted on the average of the results of each test. It can be, therefore, be inferred that the failure mechanism is not dependent on the number of nuggets. 
Furthermore, Figure 16 reveals that a proportional relation between the number of nuggets and the UTSF does not exist. For example, when the numbers of nuggets increases from 1 to 3, the UTSF increases triple times; on the other hand, UTSF of the specimen with 4 nuggets is 3.7 times more than a single nugget. In addition, the UTSF of 6 nuggets is 4.3 times more than a single nugget. To explain this non-linear relationship, an arbitrary arrangement of a weld with $n$ nuggets could be considered as shown in Figure 17 and analytical approach is describe in section 6.4.

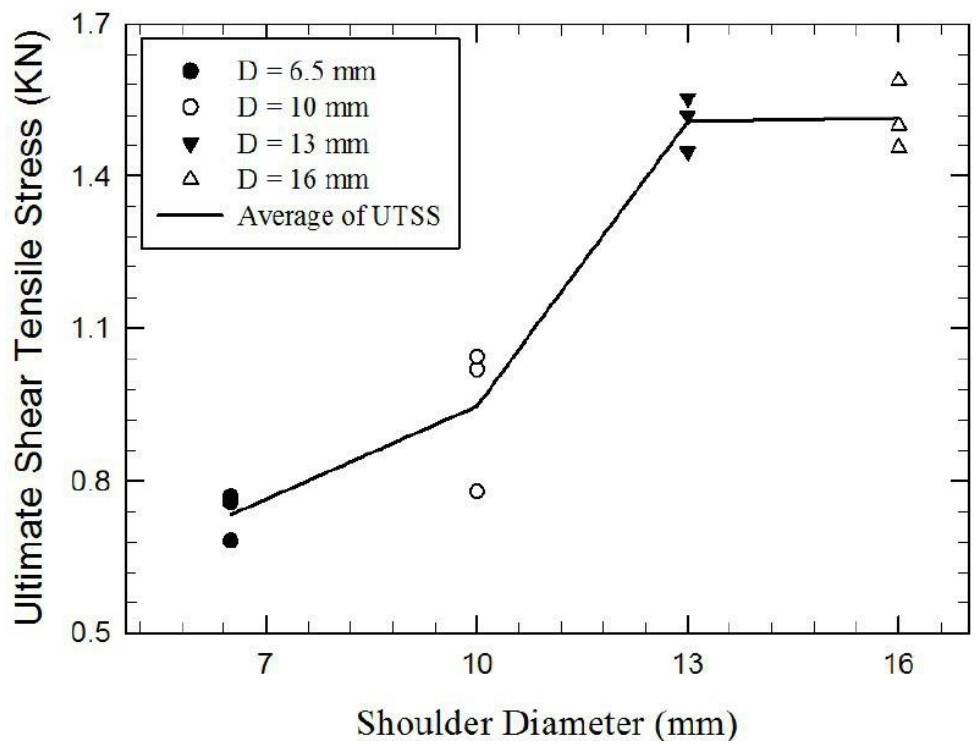

Figure 15 Scatter diagram of ultimate tensile-shear strength (UTSS) for all tested samples versus tool shoulder diameter; linear diagram of average of UTSS versus tool shoulder diameter also is drawn

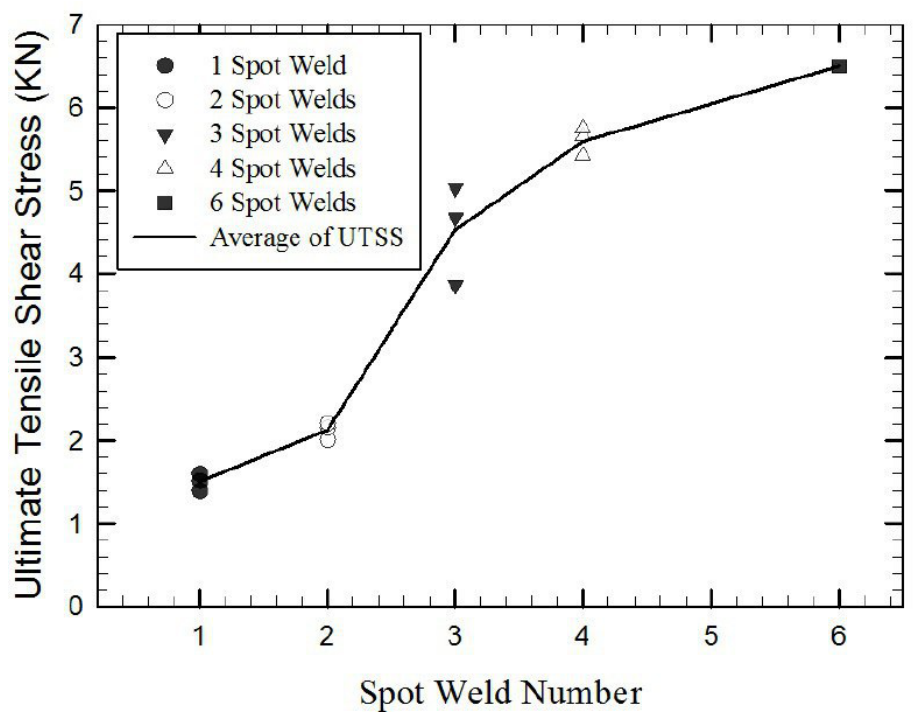

Figure 16 Scatter diagram of ultimate tensile-shear strength (UTSS) for all tested samples versus number of spot welds; Linear diagram of average of UTSS versus spot welds number also is drawn 


\section{6-3- Hardness Testing and FE Predictions}

A typical "W" shape diagram was obtained by micro-hardness measurement (Fig.9). It illustrated that the hardness of the welded regions were lower than the hardness of the base metal (BS). The micro-hardness of BS dropped from $80 \mathrm{VH}$ to a minimum value of $50 \mathrm{HV}$ in HAZ. With proximity to the keyhole, the hardness of SZ and TMAZ increased. Variety in hardness of the welded 5052 aluminum alloy, which contains a small percentage of magnesium, can be explained by the size of grains in a different zone of the weld profile (Zhang et al. 2011). The SZ and TMAZ were exposed to severe plastic deformations and high temperatures; thus, dynamic recrystallization occurred in their microstructure. Owing to this phenomenon, smaller homogenous grains were generated. Such homogeneity in grains could not be seen in HAZ. In fact, the grains in HAZ got coarser and larger than the grains of the $\mathrm{BM}$ because $\mathrm{HAZ}$ was affected by the generated heat from friction. Thus, more coarse grains reduced Vickers hardness in HAZ. Based on the Hall-Petch relationship, the reduction of grain size in a zone enhances its hardness; thus, the hardness of SZ and TMAZ are higher than HAZ (Badarinarayan et al. 2009). On the other hand, the hardness of all the zones whose materials were modified by welding was lower than the hardness of the base metal. This behavior occurs because of the decrease in density of dislocations in the welded zone due to recrystallization and exposure to heat (Zhang et al. 2011). In FSSW, the grains grew as a result of extreme heat produced in the welded zone. Dislocations occurred in grain boundaries, which prevented grain growth and their accumulation near dislocations (Nazari et al. 2015). Hence, as the density of the dislocations in the welded zone decreased, the effect of heat energy became dominant and the hardness of the heated zone became lower than the base metal.

In addition, a drop in UTSF after an increment in the shoulder diameter was reported (Bilici 2012). Generally, it can be stated that as the diameter increased, more heat were input and more materials were stirred. After a critical shoulder diameter (13 $\mathrm{mm}$ in this study), this deleterious factor became predominant and prevented an increase of UTSF.

The results indicated that when the tensile stresses were applied to the specimens, the coupon rotated so that weld nugget endured a combination of tensile and shear stress.

\section{6-4 Analytical Approach for Tensile-shear Strength of Multi-FSSW-ed Joints}

In most industrial practices, the FSSW joints consist of multi-spot welds rather than single FSSW. However, there is a lack of information on the tensile-shear strength behavior of multi-FSSW. Hence, an analytical approach is presented here to justify the obtained experimental results.

An arbitrary FSSW arrangement, with the similar weld nuggets, is shown in Figure 17. The total applied external force on the joint can be replaced with an applied force and an out-of-plane moment applied on the centroid of the weld group, G. This force and moment can be substituted with equivalent forces on each of the weld nuggets. The out-of-plane moment, M1, generates an additional load on each weld nugget as follows: 
$M_{1}=F_{A}^{\prime \prime} r_{A}+F_{B}^{\prime \prime} r_{B}+F_{C}^{\prime \prime} r_{C}+\ldots$

, where $\mathrm{r}$ is the radial distance from the centroid to the center of each weld nugget and $\mathrm{F}^{\prime \prime}$ is the substitution force. The force taken by each nugget depends upon its radial distance from the centroid, that is, the nugget farthest from the centroid bears the greatest load; the nearest nugget bears the lightest load. We can, therefore, write

$\frac{F_{A}^{\prime \prime}}{r_{A}}=\frac{F_{B}^{\prime \prime}}{r_{B}}=\frac{F_{C}^{\prime \prime}}{r_{C}}$

Solving Equations (1) and (2), simultaneously, we obtain

$F_{n}^{\prime \prime}=\frac{M_{1} r_{n}}{r_{A}^{2}+r_{B}^{2}+r_{C}^{2}+\ldots}$

, where the subscript $n$ refers to the particular nugget, whose load is to be found.

It can be seen from Equation (3) that there is a linear relationship between moment loads and the distances from the centroid for each nugget. In other words, all the nuggets do not carry the same load and the arrangement of the weld nuggets has a significant effect on the load carrying capacity of the welded joints. In the linear arrangement of the current research, the weld centroid is between two weld nuggets when the number of the nuggets is even. The centroid will be coincident with the weld nugget when the number of weld nuggets is odd.

From the results presented in Figure 16, it is evident that sharp increases in UTSF occurred when the number of nuggets became an odd number from a prior even number. For example, the UTSF for a joint with 2, 3, and 4 nuggets is $1.41 \mathrm{KN}, 2.99 \mathrm{KN}$, and $3.70 \mathrm{KN}$, respectively. The ultimate strength increased by 113 percent when the two nuggets became three nuggets, but the ultimate strength increased by only 23 percent when three nuggets were increased to four nuggets. When the number of nuggets is odd, the centroid crosses on to one of the nuggets; then, the effect of moment on the central nugget was not significant and this nugget endured greater forces. It is, therefore, better for the joints to be designed with an odd number of nuggets in a linear arrangement. 


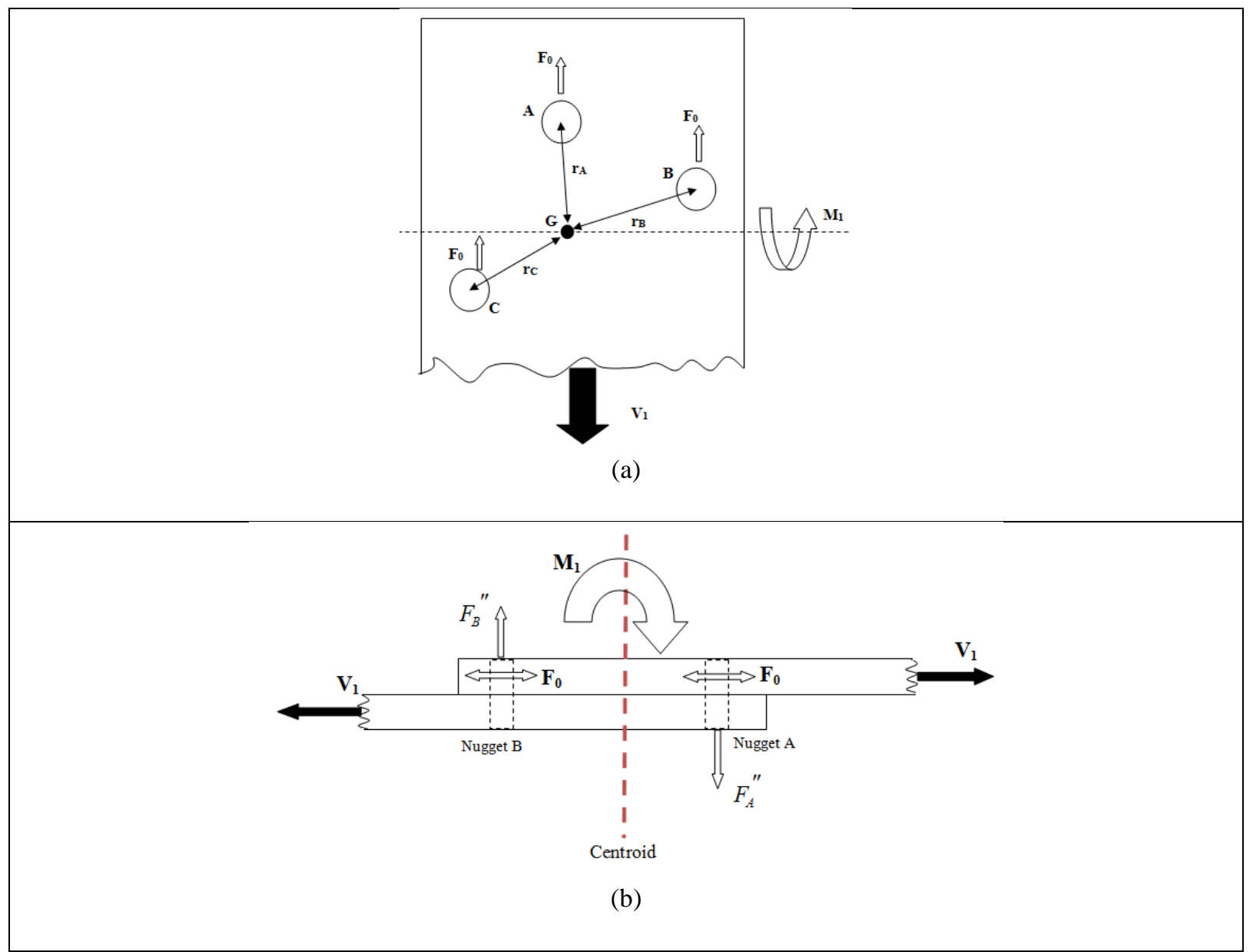

Figure 17. The applied forces of each nuggets, the $\mathrm{O}$ shows the centroid, (a) top view of a specimen (b) side view of a specimen

\section{Conclusions}

1. A simple FE model was developed that could predict the UTSF of single and multi-friction stir spot welded joints, which were welded by tools with different shoulders.

2. The effects of the shoulder diameter and the number of nuggets on the UTSF were explored. Indeed, under special conditions, increasing the shoulder diameter was better than increasing the number of nuggets. After a critical diameter, however, the UTSF did not increase.

3. The arrangement of nuggets in multi-spot specimens was a significant factor to determine the UTSF of the weld. In this paper, multi-spot specimens were analyzed mathematically to describe the best arrangement for multi-spot specimens.

4. The fracture mechanism involved the shear method and this was determined by both metallurgical analyses and force-displacement diagrams. In this mechanism, the parts of the specimen were disjointed from the interfaces of the two plates by a shear force. 


\section{Acknowledgment}

The authors gratefully acknowledge funding from K.N.Toosi University of Technology and we are pleased to acknowledge the benefit of technical discussions with Mr. M. Naeim at the Mechanical Engineering workshop at K.N.Toosi University of Technology.

\section{References}

Addison, A. and A. Robelou (2004). Friction stir spot welding: principal parameters and their effects. Proceedings of the 5th International Friction Stir Welding Symposium, sponsored by TWI, Ltd., Metz, France.

Adib, H., J. Gilgert and G. Pluvinage (2004). "Fatigue life duration prediction for welded spots by volumetric method." International Journal of Fatigue 26(1): 81-94.

Awang, M. and V. H. Mucino (2010). "Energy generation during friction stir spot welding (FSSW) of Al 6061-T6 plates." Materials and Manufacturing Processes 25(1-3): 167-174.

Badarinarayan, H., Y. Shi, X. Li and K. Okamoto (2009). "Effect of tool geometry on hook formation and static strength of friction stir spot welded aluminum 5754-O sheets." International Journal of Machine Tools and Manufacture 49(11): 814-823.

Badarinarayan, H., Q. Yang and S. Zhu (2009). "Effect of tool geometry on static strength of friction stir spot-welded aluminum alloy." International Journal of Machine Tools and Manufacture 49(2): 142-148.

Bilici, M. K. (2012). "Effect of tool geometry on friction stir spot welding of polypropylene sheets." Express Polym Lett 6(10): 805-813.

Bilici, M. K. and A. I. Yükler (2012). "Influence of tool geometry and process parameters on macrostructure and static strength in friction stir spot welded polyethylene sheets." Materials \& Design 33: 145-152.

Bozzi, S., A. Helbert-Etter, T. Baudin, V. Klosek, J. Kerbiguet and B. Criqui (2010). "Influence of FSSW parameters on fracture mechanisms of 5182 aluminium welds." Journal of Materials Processing Technology 210(11): 1429-1435.

Dörfler, S. M. (2008). Advanced modeling of friction stir welding-improved material model for aluminum alloys and modeling of different materials with different properties by using the level set method. Comsol Multiphysics European Conference.

Fanelli, P., F. Vivio and V. Vullo (2012). "Experimental and numerical characterization of Friction Stir Spot Welded joints." Engineering Fracture Mechanics 81: 17-25.

Feng, Z., M. Santella, S. David, R. Steel, S. Packer, T. Pan, M. Kuo and R. Bhatnagar (2005). Friction Stir Spot Welding of advanced high-strength steels-a feasibility study, SAE Technical Paper.

Gerlich, A., P. Su and T. North (2005). "Tool penetration during friction stir spot welding of Al and Mg alloys." Journal of Materials Science 40(24): 6473-6481.

Hancock, R. (2004). "Friction welding of aluminum cuts energy costs by 99\%." WELDING JOURNALNEW YORK- 83(2): 40-43.

Hassanifard, S., S. Rash Ahmadi and M. Mohammad Pour (2013). "Weld arrangement effects on the fatigue behavior of multi friction stir spot welded joints." Materials \& Design 44: 291-302.

Khosa, S. U., T. Weinberger and N. Enzinger (2010). "Thermo-mechanical investigations during friction stir spot welding (FSSW) of AA6082-T6." Welding in the World 54(5-6): R134-R146.

Langerman, M. and K. Edvin (2003). TED-AJ03-133 Modeling Plasticized Aluminum Flow and Temperature Fields During Friction Stir Welding. Proceedings of the... ASME/JSME Thermal Engineering Joint Conference, 一般社団法人日本機械学会.

Lin, P.-C., Z.-M. Su, R.-Y. He and Z.-L. Lin (2012). "Failure modes and fatigue life estimations of spot friction welds in cross-tension specimens of aluminum 6061-T6 sheets." International Journal of Fatigue 38: 25-35. 
Lin, Y.-C., J.-J. Liu and J.-N. Chen (2013). "Material flow tracking for various tool geometries during the friction stir spot welding process." Journal of materials engineering and performance 22(12): 3674-3683.

Marya, M., K. Wang, L. G. Hector and X. Gayden (2006). "Tensile-shear forces and fracture modes in single and multiple weld specimens in dual-phase steels." Journal of manufacturing science and engineering 128(1): 287-298.

Mishra, R. S. and Z. Ma (2005). "Friction stir welding and processing." Materials Science and Engineering: R: Reports 50(1-2): 1-78.

Nazari, M., M. K. B. Givi, M. R. Farahani, J. M. Milani and H. M. Jamaliyan (2015). "Investigation on the effects of using Nano-size Al2O3 powder on the mechanical and microstructural in the multipasses continuous friction stir welding of the 2024-T6." Modares Mechanical Engineering 14(12).

Paidar, M., A. Khodabandeh, H. Najafi and A. S. Rouh-aghdam (2014). "Effects of the tool rotational speed and shoulder penetration depth on mechanical properties and failure modes of friction stir spot welds of aluminum 2024-T3 sheets." Journal of Mechanical Science and Technology 28(12): 4893-4898.

Pan, T.-Y. (2007). Friction Stir Spot Welding (FSSW)-A Literature Review, SAE Technical Paper.

Sarkar, R., T. Pal and M. Shome (2016). "Material flow and intermixing during friction stir spot welding of steel." Journal of Materials Processing Technology 227: 96-109.

Su, P., A. Gerlich, T. North and G. Bendzsak (2007). "Intermixing in dissimilar friction stir spot welds." Metallurgical and materials transactions A 38(3): 584-595.

Tozaki, Y., Y. Uematsu and K. Yokaji (2006). Effect of welding condition on tensile strength of dissimilar friction stir spot welds between different aluminum alloys. 6th International Symposium on Friction Stir Welding (ISFSW6), Montreal, QC, Canada, Oct.

Yang, X., T. Fu and W. Li (2014). "Friction stir spot welding: a review on joint macro-and microstructure, property, and process modelling." Advances in Materials Science and Engineering 2014.

Zhang, Z., X. Yang, J. Zhang, G. Zhou, X. Xu and B. Zou (2011). "Effect of welding parameters on microstructure and mechanical properties of friction stir spot welded 5052 aluminum alloy." Materials \& Design 32(8): 4461-4470. 
Figures

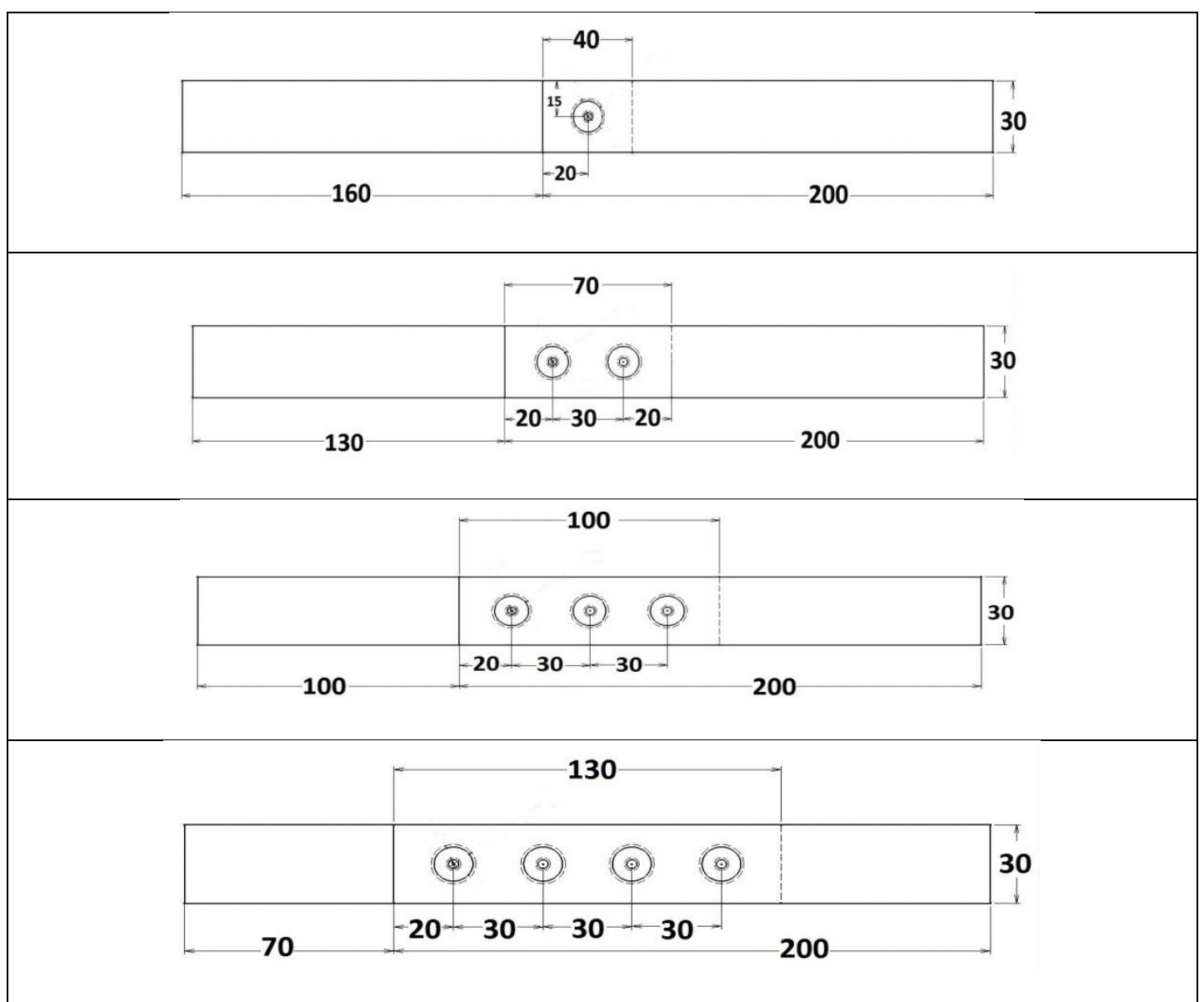

Figure 1 Dimension of multiple FSSW specimen with 4 spot welds (Dimensions are in mm.) 


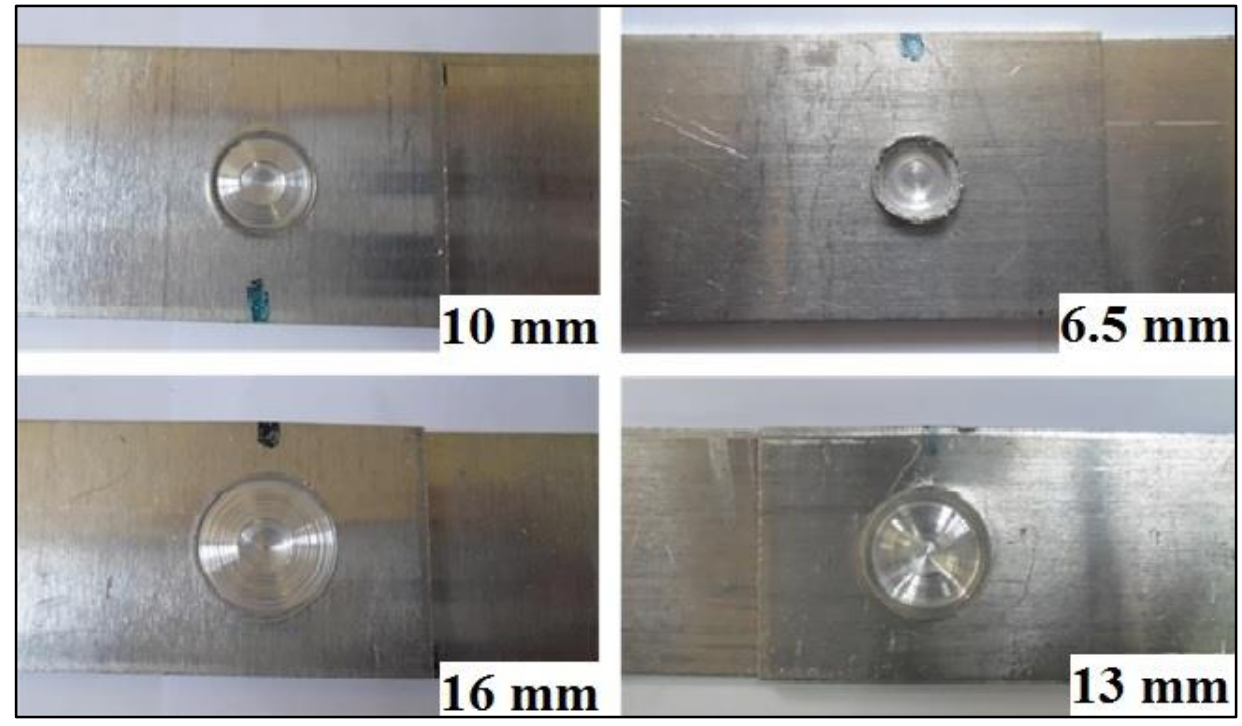

Figure 2 Welded specimens with single spot weld and different tools shoulder diameter 


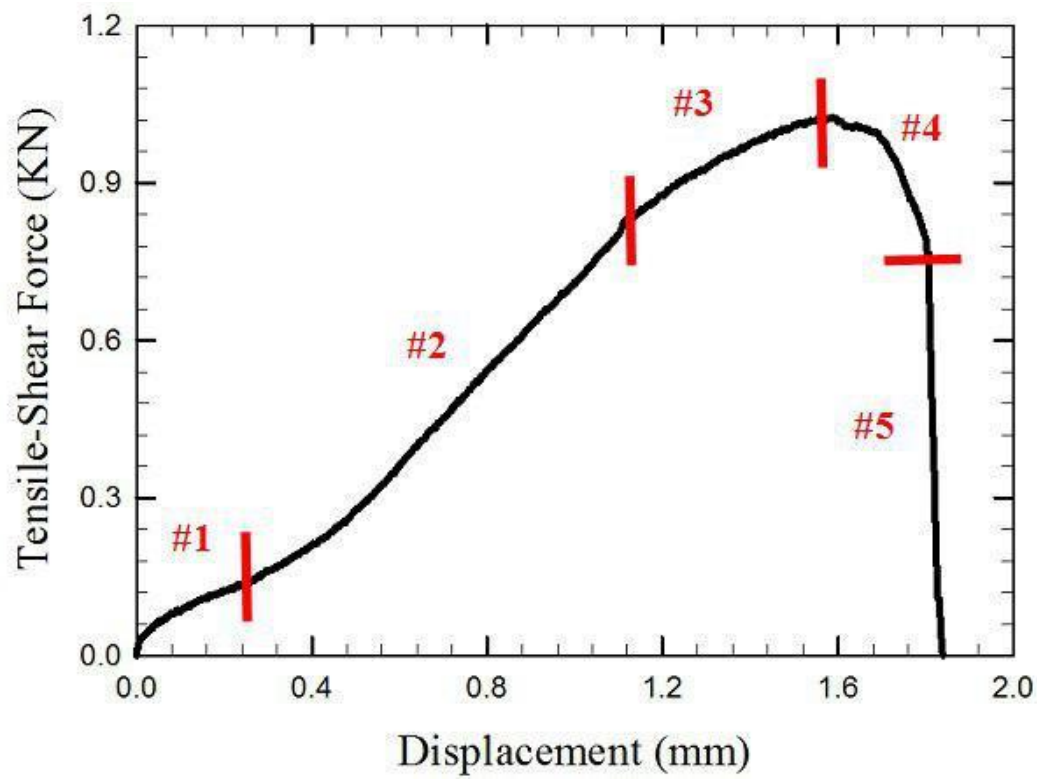

Figure 3 Force-displacement curve for one spot welded specimen. \#1: gripping and balancing the specimen; \#2: elastic deformation; \#3: weld nugget rotation and reaching to UTTS; \#4: shear fracture; \#5: joint separation 


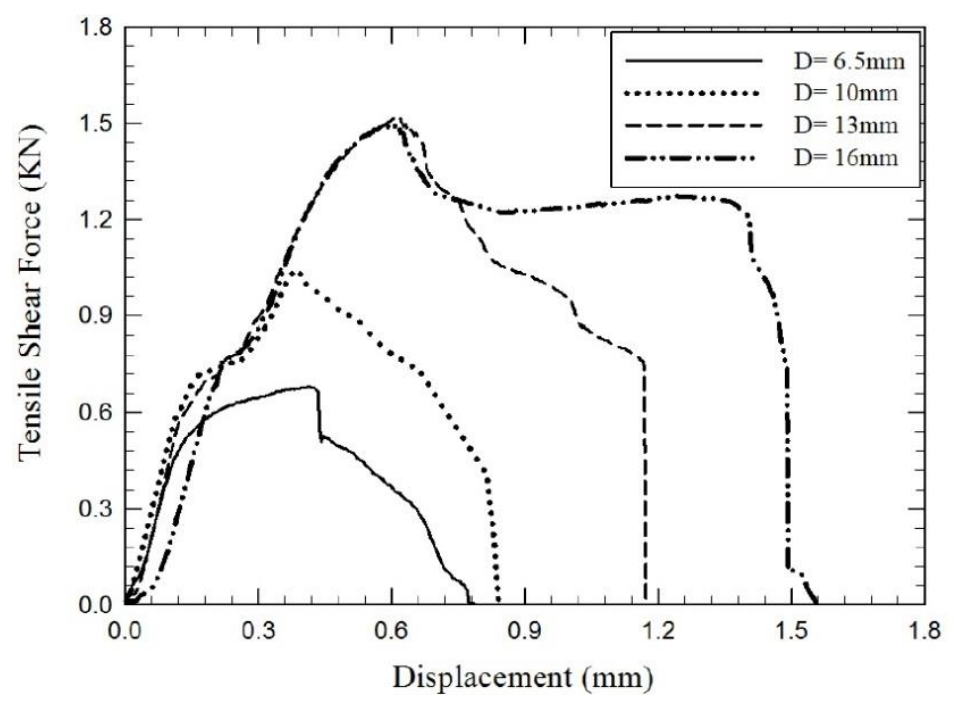

Figure 4 Force-displacement curves for spot welds produced by tools having various shoulder diameters 


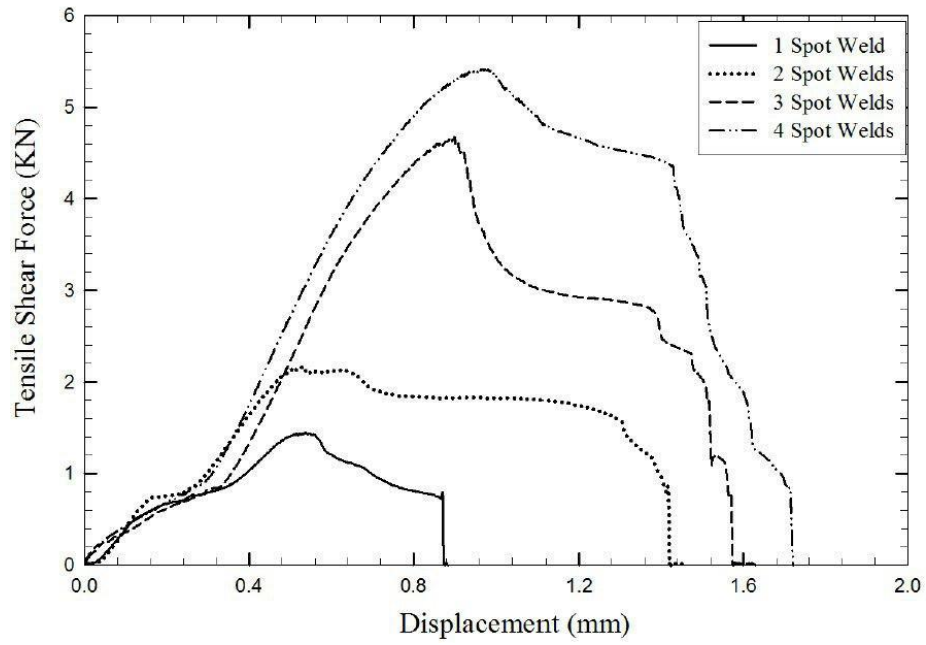

Figure 5 Force-displacement curves for multiple Spot welds 


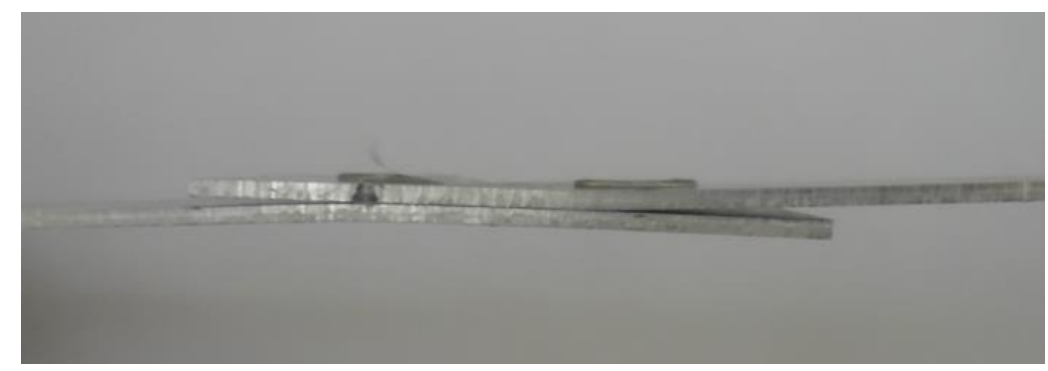

Figure 6 Side view of deformation in the FSSW specimen with two spot weld 


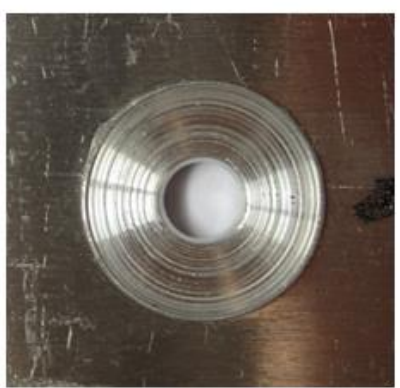

(a)

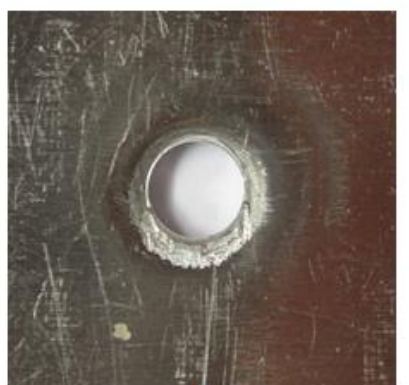

(b)

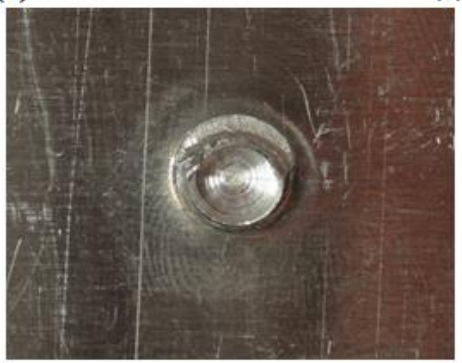

(c)

Figure 7 Surfaces of the failed specimen under tensile shear load, (a) the upside of upper surface, (b) the downside of upper surface, (c) the upside of upper surface 


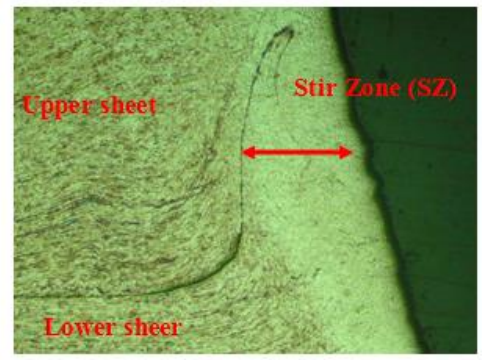

(a)

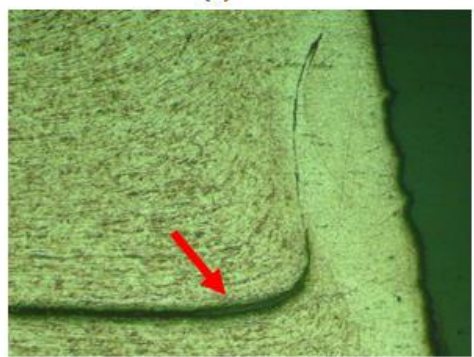

(c)

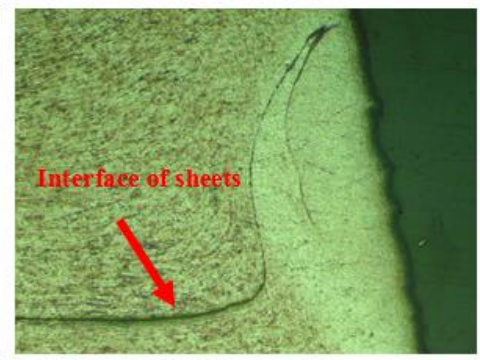

(b)

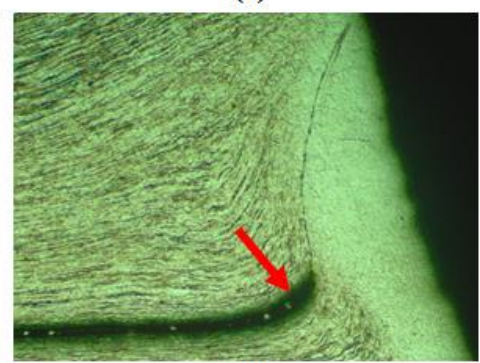

(d)

Figure 8 Macrostructure views of side of the nugget reperesented to (a) section \#1, (b) section \#2, (c) section \#3, (d) section \#4 


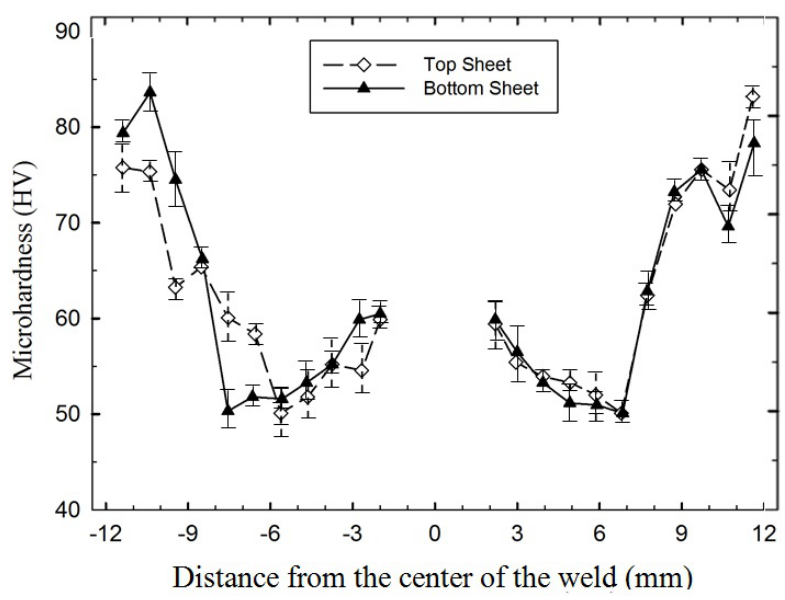

Figure 9 Micro-hardness variations across welding spot for specimen No.3 


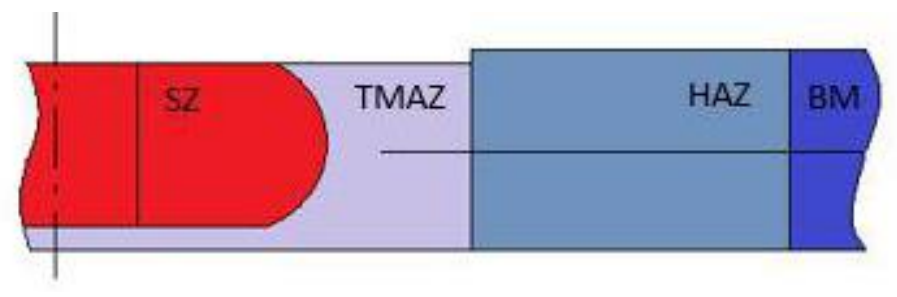

Figure 10 Different zones in FE model 


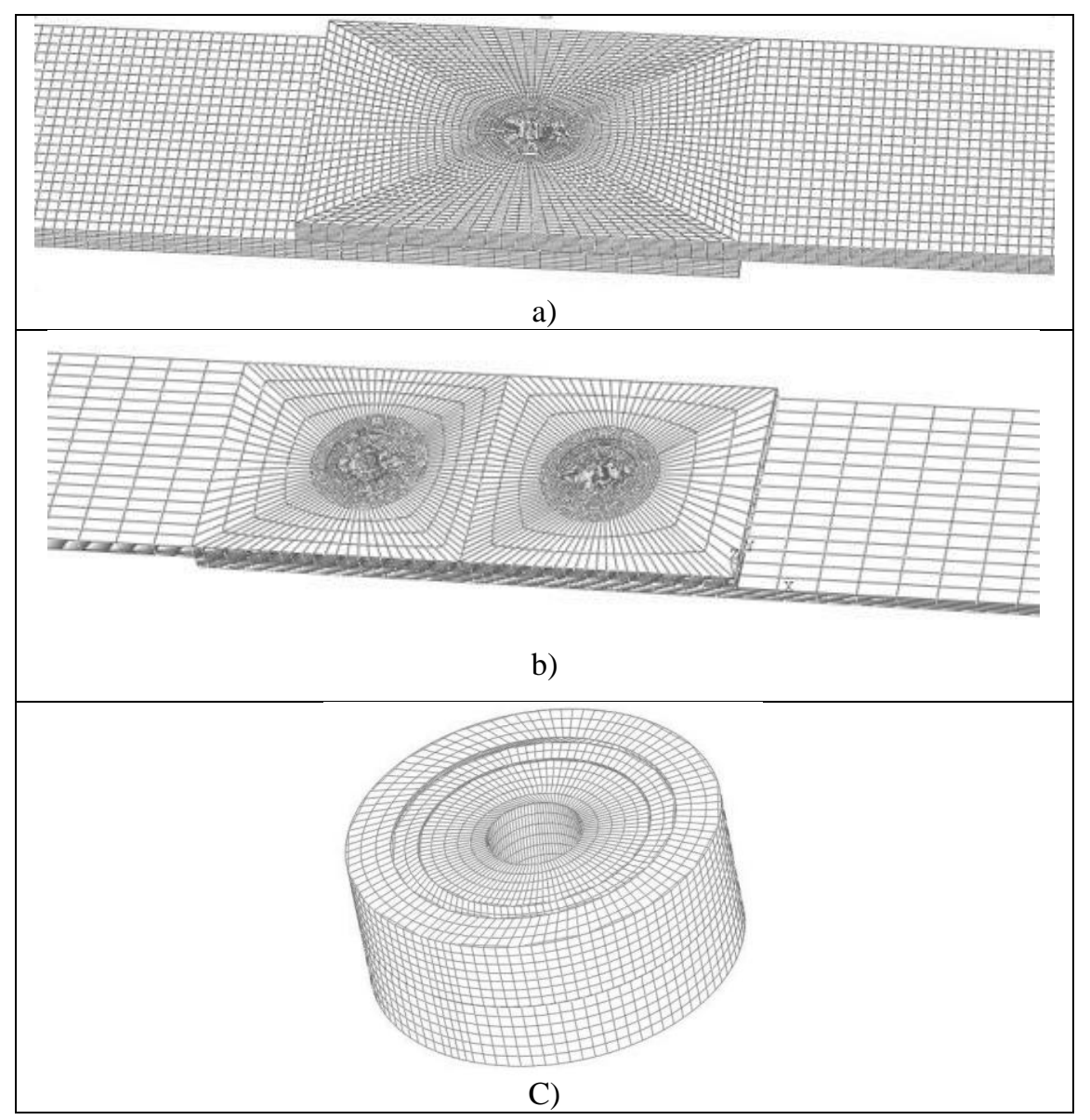

Figure 11 FE Mesh a) single spot b)double spot c) details of FE mesh in the HAZ area 


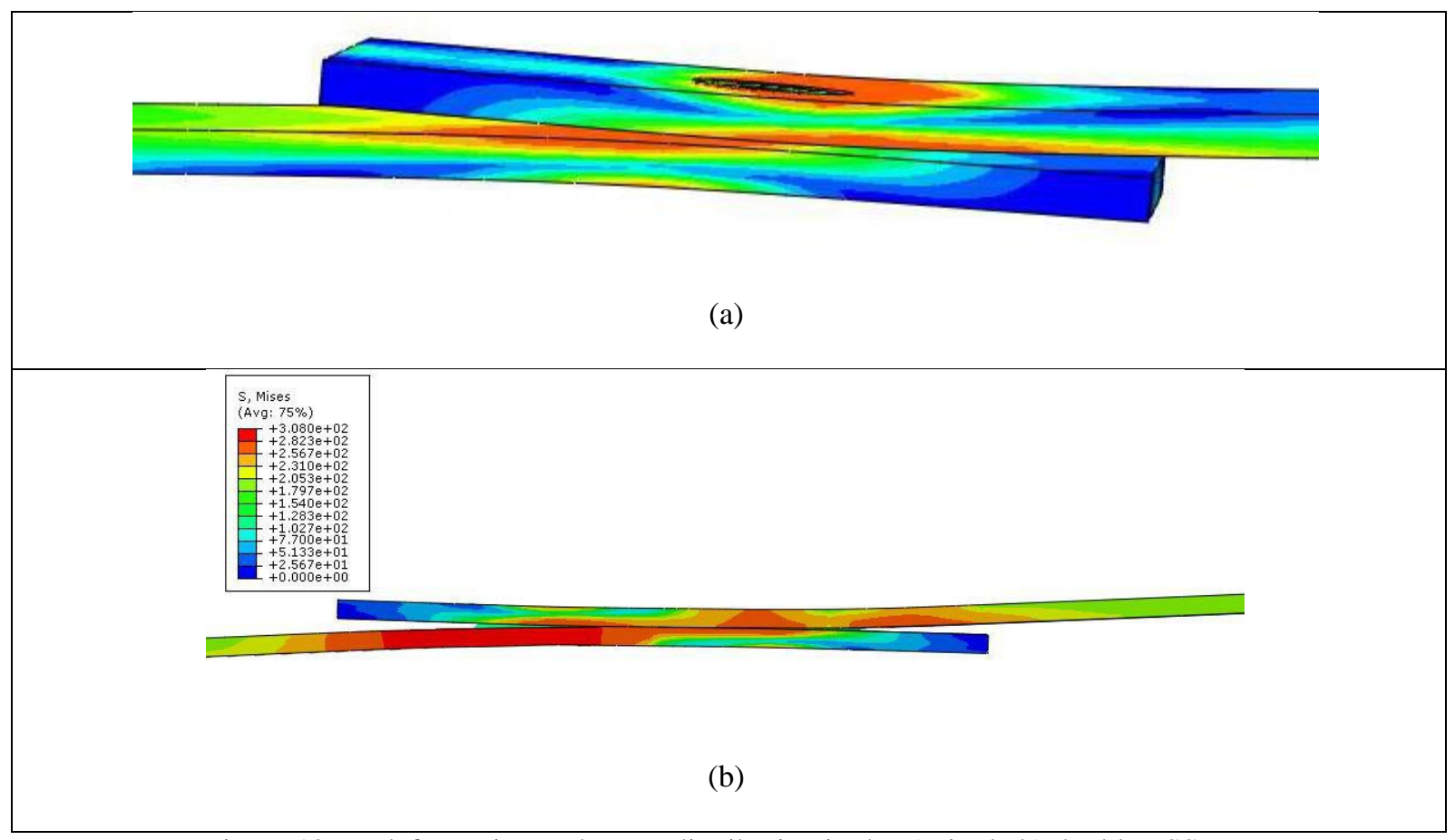

Figure $12 \mathrm{FE}$ deformation and stress distribution in the a) single b) double FSSW 


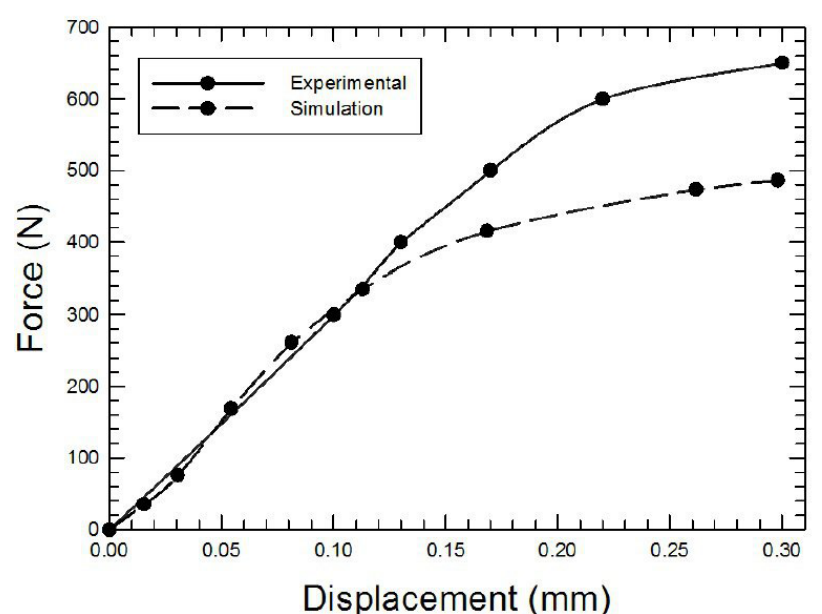

a)

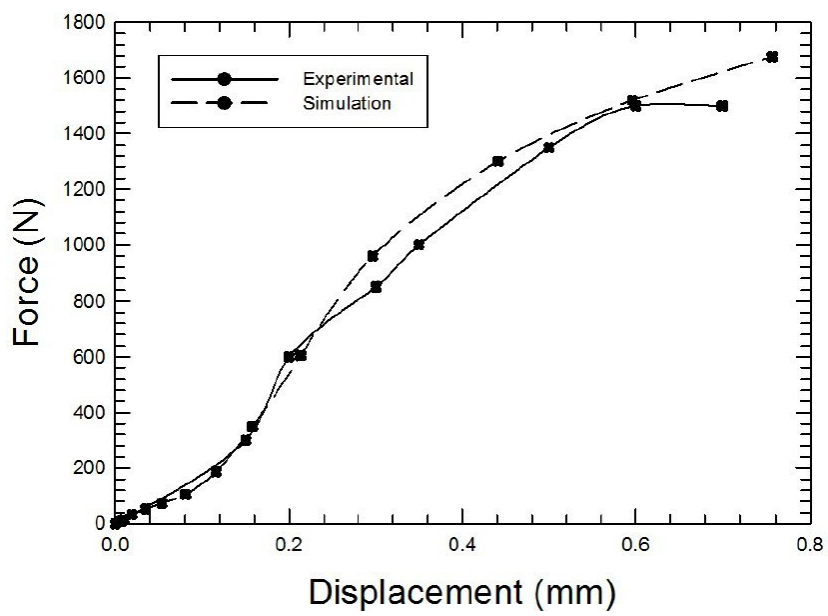

c)

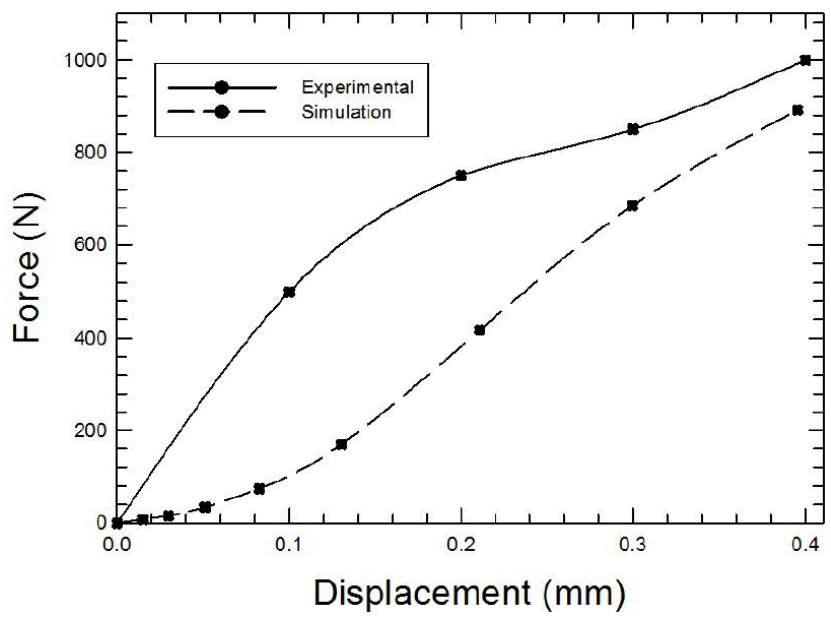

b)

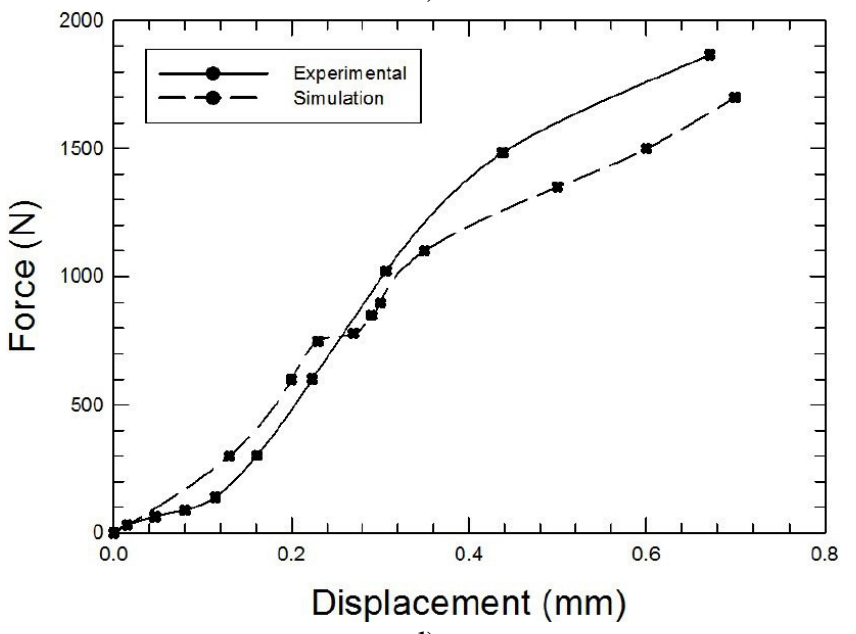

d)

Figure 13 Comparison between experiment and FE simulation a) $6.5 \mathrm{~mm} \quad$ b) $10 \mathrm{~mm} \quad$ c) $13 \mathrm{~mm}$ d) $16 \mathrm{~mm}$ 


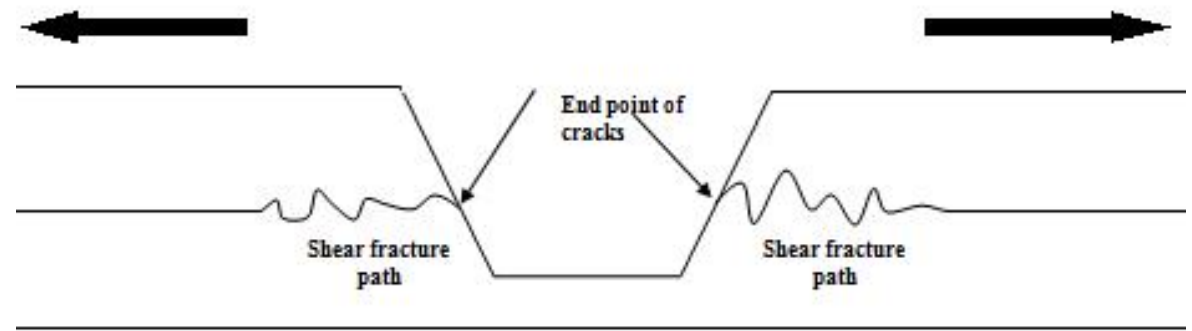

(a)

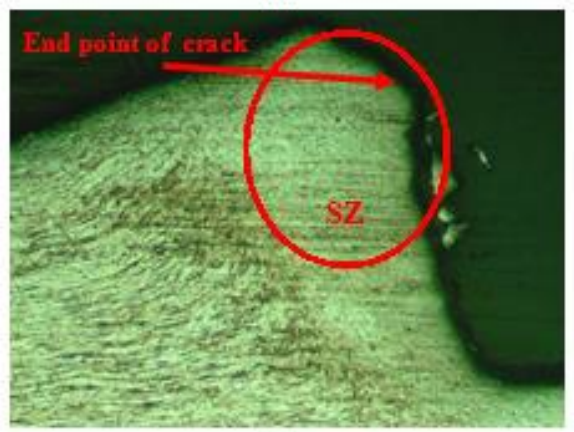

(b)

Figure 14. The crack propagation path under tensile-shear loadings 


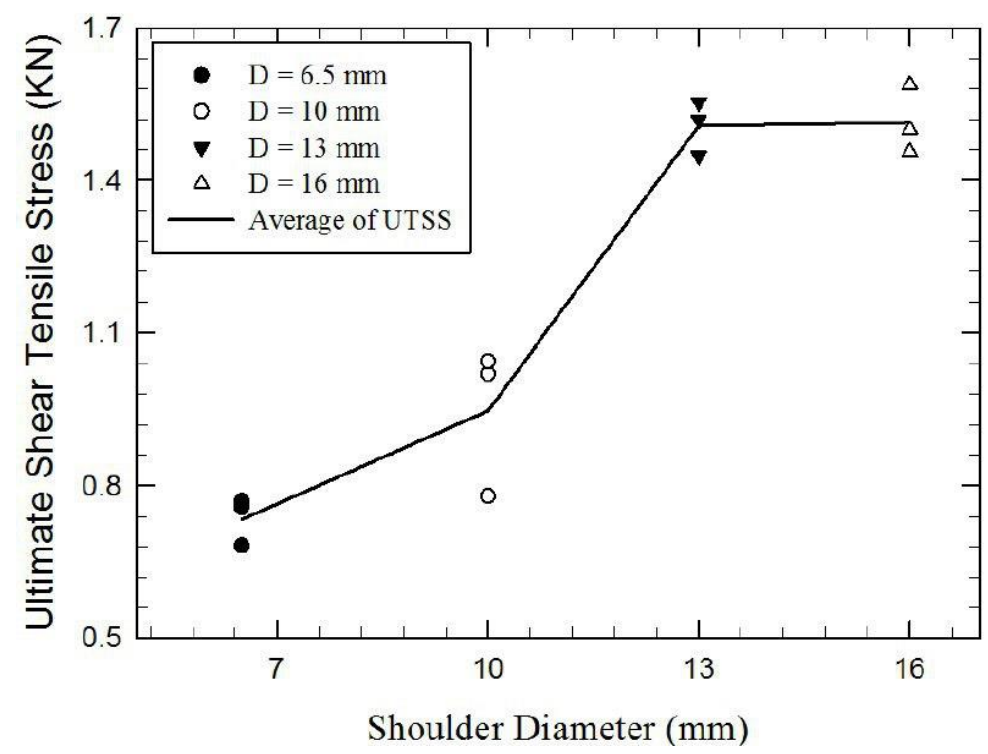

Figure 15 Scatter diagram of ultimate tensile-shear strength (UTSS) for all tested samples versus tool shoulder diameter; linear diagram of average of UTSS versus tool shoulder diameter also is drawn 


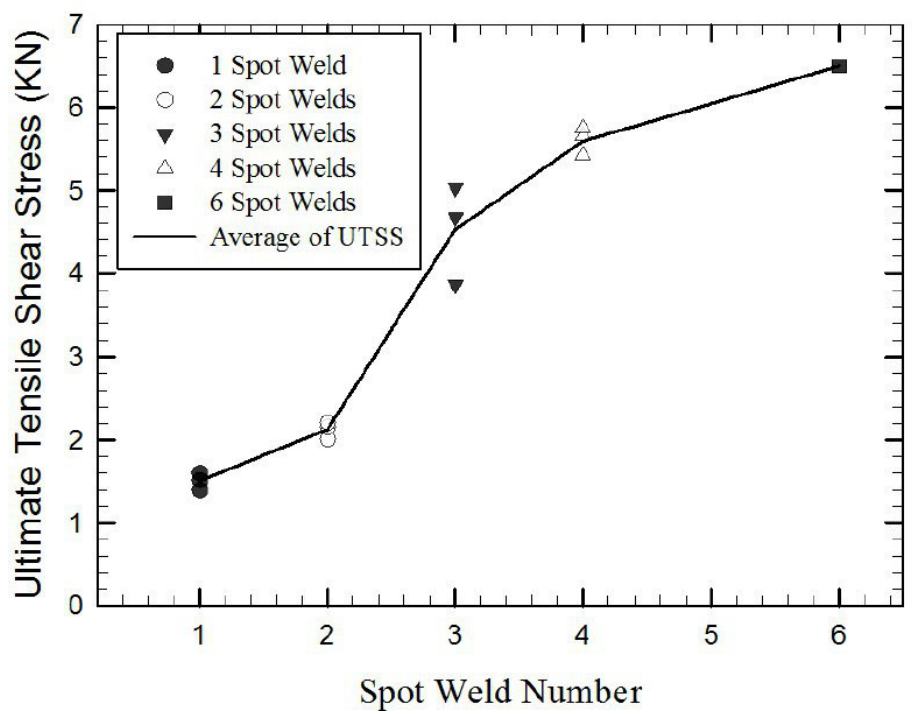

Figure 16 Scatter diagram of ultimate tensile-shear strength (UTSS) for all tested samples versus number of spot welds; Linear diagram of average of UTSS versus spot welds number also is drawn 


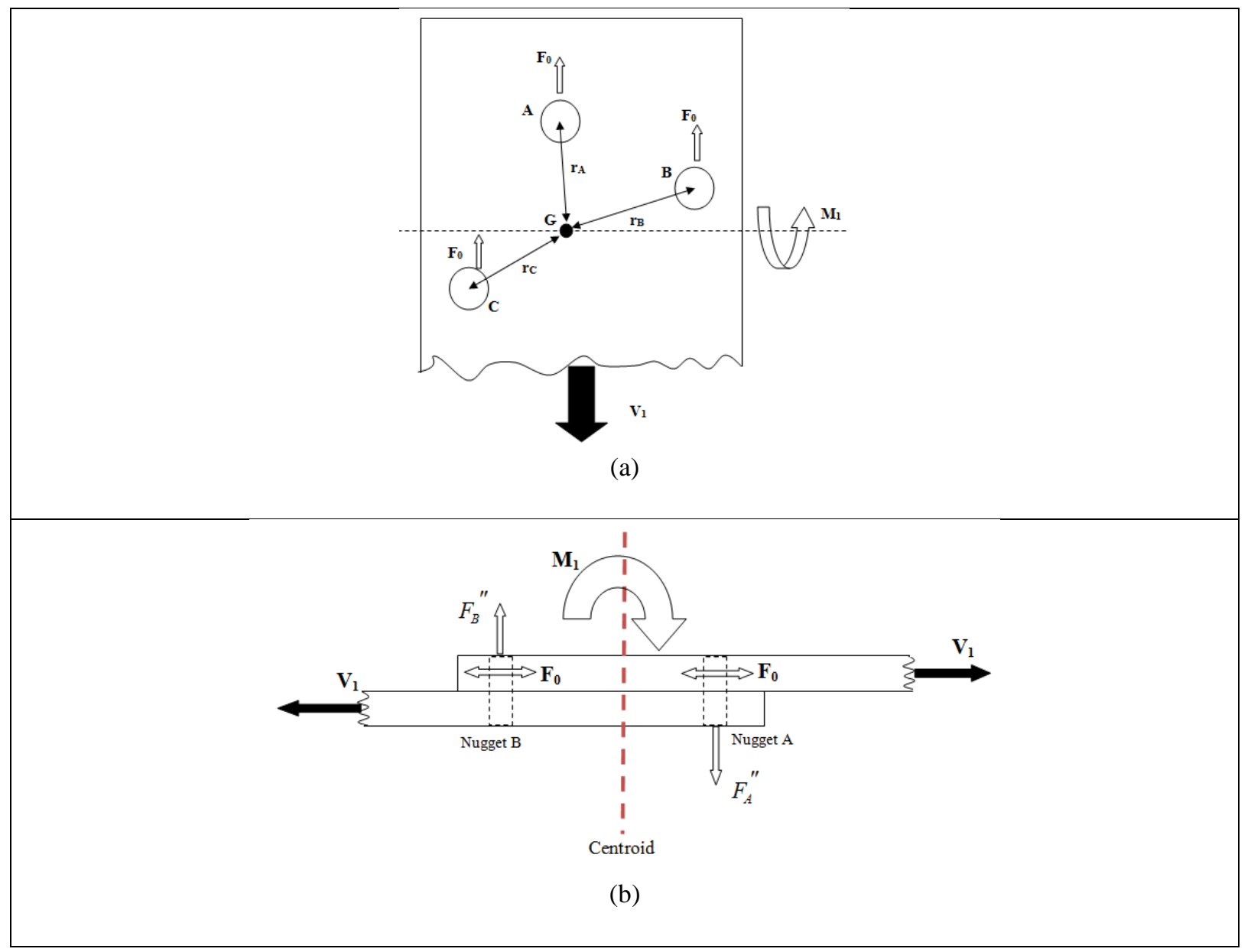

Figure 17. The applied forces of each nuggets, the $\mathrm{O}$ shows the centroid, (a) top view of a specimen (b) side view of a specimen 